\title{
Calcitonin Gene-Related Peptide-Mediated Enhancement of Purinergic Neuron/Glia Communication by the Algogenic Factor Bradykinin in Mouse Trigeminal Ganglia from Wild- Type and R192Q $\mathrm{Ca}_{\mathrm{v}} 2.1$ Knock-In Mice: Implications for Basic Mechanisms of Migraine Pain
}

\author{
Stefania Ceruti, ${ }^{1 \star}$ Giovanni Villa, ${ }^{1 \star}$ Marta Fumagalli, ${ }^{1}$ Laura Colombo, ${ }^{1}$ Giulia Magni, ${ }^{1}$ Matteo Zanardelli, ${ }^{1}$ \\ Elsa Fabbretti, ${ }^{2,3}$ Claudia Verderio, ${ }^{4}$ Arn M. J. M. van den Maagdenberg, ${ }^{5}$ Andrea Nistri, ${ }^{2}$ and Maria P. Abbracchio ${ }^{1}$ \\ ${ }^{1}$ Department of Pharmacological Sciences, University of Milan, 20133 Milan, Italy, ${ }^{2}$ Neurobiology Sector and Italian Institute of Technology Unit, \\ International School for Advanced Studies, 34136, Trieste, Italy, ${ }^{3}$ Laboratory for Environmental Science, University of Nova Gorica, SI-5000 Nova Gorica, \\ Slovenia, ${ }^{4}$ Department of Medical Pharmacology, CNR Institute of Neuroscience, University of Milan, 20129 Milan, Italy, and ${ }^{5}$ Departments of Human \\ Genetics and Neurology, Leiden University Medical Centre, 2300 RC, Leiden, The Netherlands
}

Within the trigeminal ganglion, crosstalk between neurons and satellite glial cells (SGCs) contributes to neuronal sensitization and transduction of painful stimuli, including migraine pain, at least partly through activation of purinergic receptor mechanisms. We previously showed that the algogenic mediator bradykinin (BK) potentiates purinergic P2Y receptors on SGCs in primary trigeminal cultures. Our present study investigated the molecular basis of this effect in wild-type (WT) mice and Ca $2.1 \alpha 1 \mathrm{R} 192 \mathrm{Q}$ mutant knock-in (KI) mice expressing a human mutation causing familial hemiplegic migraine type 1. Single-cell calcium imaging of WT cultures revealed functional BK receptors in neurons only, suggesting a paracrine action by BK to release a soluble mediator responsible for its effects on SGCs. We identified this mediator as the neuropeptide calcitonin gene-related peptide (CGRP), whose levels were markedly increased by $\mathrm{BK}$, while the CGRP antagonist $\mathrm{CGRP}_{8-37}$ and the anti-migraine drug sumatriptan inhibited $\mathrm{BK}$ actions. Unlike CGRP, BK was ineffective in neuron-free SGC cultures, confirming the CGRP neuronal source. P2Y receptor potentiation induced by CGRP in SGCs was mediated via activation of the extracellular signal-regulated kinase $1 / 2$ pathways, and after exposure to CGRP, a significant release of several cytokines was detected. Interestingly, both basal and BK-stimulated CGRP release was higher in KI mouse cultures, where BK significantly upregulated the number of SGCs showing functional UTP-sensitive P2Y receptors. Our findings suggest that P2Y receptors on glial cells might be considered as novel players in the cellular processes underlying migraine pathophysiology and might represent new targets for the development of innovative therapeutic agents against migraine pain.

\section{Introduction}

Migraine is a common neurovascular disorder affecting $>12 \%$ of adults in the Western World (Goadsby et al., 2002) and characterized by recurrent attacks of severe headaches with associated autonomic symptoms (Headache Classification Subcommittee of the International Headache Society, 2004). Two main mi-

\footnotetext{
Received Dec. 10, 2010; revised; accepted Jan. 3, 2011.

This work was supported by the Italian Comitato Telethon Fondazione onlus, Grant GGP07032 entitled: "Genetic and micro-environmental factors regulate the role of ATP as transmitter of pain in a migraine model" and Grant GGP10082 entitled: "Studies of familial hemiplegic migraine transgenic mouse models and patients to investigate the crosstalk between sensory neurons and neuroinflammatory cells in trigeminal ganglia in relation to migraine pain" to A.N. and M.P.A., and by a grant from the Centre for Medical Systems Biology within the framework of the Netherlands Genomics Initiative (NGI)/Netherlands Organization for Scientific Research (NWO) to A.vdM.

*S.C. and G.V. are equally contributing authors.

Correspondence should be addressed to Maria P. Abbracchio, Department of Pharmacological Sciences, University of Milan, via Balzaretti 9, 20133 Milan, Italy. E-mail: mariapia.abbracchio@unimi.it.

DOI:10.1523/JNEUROSCI.6440-10.2011

Copyright $\odot 2011$ the authors $\quad 0270-6474 / 11 / 313638-12 \$ 15.00 / 0$
}

graine types are defined based on the absence or presence of an aura (i.e., transient visual, sensory- and/or speech-related neurological symptoms). Whereas it is understood that cortical spreading depression (CSD) causes the aura (Lauritzen, 1994), the headache mechanisms are less clear. Peripheral sensitization of trigeminal ganglion (TG) sensory neurons and concomitant increased release of calcitonin gene-related peptide (CGRP) are thought to play an important role by activating second-order neurons that mediate central sensitization (Messlinger, 2009).

Several data clearly indicate that TG neurons act in strict synergy with non-neuronal satellite glial cells (SGCs), which envelop neuronal bodies to constitute a functional unit within the ganglion (Hanani, 2005). Thus, cross communication involving both gap junctions (Thalakoti et al., 2007) and paracrine signaling increases the excitability of primary neurons and contributes to the development of hyperalgesia and allodynia (Takeda et al., 2009). Although various proinflammatory mediators are released within the TG (Takeda et al., 2009), the whole molecular network 
at the basis of the neuron-to-SGC interplay, and its involvement in migraine pain mechanisms, are still largely unknown. Therefore, its identification could possibly yield new pharmacological targets to abort or even prevent migraine attacks.

The purinergic system has recently emerged as an important player in the transmission and integration of pain sensation. Neuronal ATP-gated $\mathrm{P}_{2} \mathrm{X}_{3}$ channels are involved in the activation of peripheral nociceptors (Burnstock, 2006); a role is also emerging for $\mathrm{G}$ protein-coupled $\mathrm{P} 2 \mathrm{Y}$ receptor subtypes in the modulation of painful signals, as well as in neuron-to-glia communication both in the spinal cord and in peripheral ganglia (Jarvis, 2010). We have recently demonstrated that exposure of primary mixed TG cultures to the algogenic mediator bradykinin (BK) induces the upregulation of $\mathrm{P} 2 \mathrm{Y}$-mediated signaling in SGCs (Ceruti et al., 2008), suggesting a close interplay between the purinergic system and other classical pain transducing signals.

Here we demonstrate that CGRP released from wild-type (WT) sensory neurons is the key mediator of BK-induced P2Y receptor upregulation on SCGs, and that the latter occurs via the extracellular signal-regulated kinase 1/2 (ERK1/2) mitogenactivated protein (MAP) kinase pathway. In addition, we investigated CGRP release and potentiation of $\mathrm{P} 2 \mathrm{Y}$ receptor function by $\mathrm{BK}$ in a genetic knock-in (KI) mouse model of migraine in which an R192Q missense mutation, which causes familial hemiplegic migraine type 1 (FHM1) (Ophoff et al., 1996), was introduced in the $\alpha 1$ subunit of $\mathrm{Ca}_{\mathrm{V}} 2.1$ calcium channels by a gene targeting approach (van den Maagdenberg et al., 2004). We could show that primary TG cultures from mutant KI mice release more CGRP than WT ones, and that BK augments not only glial $\mathrm{P} 2 \mathrm{Y}$-mediated calcium responses but also the percentage of responding cells, suggesting that the observed modulation of purinergic signaling in SGCs is particularly prominent in mutant ganglia, which has implications for migraine pathophysiology.

\section{Materials and Methods}

Cell cultures and pharmacological treatments. Primary mixed neuronSGC cultures were prepared from trigeminal ganglia of P11 WT C57BL/6J mice (Charles River Laboratories) or of transgenic $\mathrm{Ca}_{\mathrm{V}} 2.1 \alpha 1$ R192Q mutant KI mice and WT littermates (van den Maagdenberg et al., 2004), as previously described (Ceruti et al., 2008). KI and WT littermates were backcrossed for at least 5 generations with C57BL/6J mice. Because of the gene targeting approach (resulting in a 129 and C57BL/6J mixed background) that was used to generate the transgenic mice, all our mice tested have at least 97\% C57BL/6J background. No difference in response phenotype was observed between C57BL/6J mice and WT littermates. Briefly, after TG excision and enzyme dissociation at $37^{\circ} \mathrm{C}$ with $0.25 \mathrm{mg} / \mathrm{ml}$ trypsin, $1 \mathrm{mg} / \mathrm{ml}$ collagenase and $0.2 \mathrm{mg} / \mathrm{ml}$ DNase (SigmaAldrich), cells were centrifuged, resuspended in culture medium (Ham's F-12 with $10 \%$ fetal calf serum and $1 \%$ penicillin/streptomycin), and plated onto poly-L-lysine-coated wells or glass coverslips. Experiments involving primary mixed neuron-SGC cultures were performed $48 \mathrm{~h}$ after plating.

SGC-purified cultures were prepared from mixed cultures at day 5 in culture, after replacing culture medium at days 1 and 3 . At day 5, cells were detached from the Petri dish by a 5 min treatment with $0.5 \%$ trypsin $/ 0.2 \%$-EDTA (Sigma-Aldrich) at $37^{\circ} \mathrm{C}$, resuspended in fresh culture medium, and replated onto uncoated wells or $24 \mathrm{~mm}$ diameter coverslips. This procedure completely removed all neurons without affecting SGC adhesion and growth (England et al., 2001; Capuano et al., 2009). The culture medium was replaced $24 \mathrm{~h}$ later, and experiments were performed after additional $24 \mathrm{~h}$.

Both primary mixed and purified SGC cultures were exposed to 100 nм BK (Sigma-Aldrich), or $1 \mu \mathrm{m}$ CGRP (Tocris Bioscience) for the indicated time periods (see Results and figures). In some experiments, CGRP receptor antagonist, $\mathrm{CGRP}_{8-37}(2 \mu \mathrm{m}$; Tocris Bioscience), ERK1/2 inhibitor 2-(2-amino-3-methoxyphenyl)-4H-1-benzopyran-4-one (PD98059) (50 $\mu \mathrm{M}$; Sigma-Aldrich), or serotonin agonist sumatriptan (10 $\mu \mathrm{M}$; SigmaAldrich) was added to the culture media $30 \mathrm{~min}$ before CGRP or BK application. The dose of CGRP and of its antagonist was selected as the most effective, as previously reported by us (Fabbretti et al., 2006). Parallel control (CTR) cells were treated with vehicle (i.e., Ham's F-12) alone.

Immunocytochemistry. Cell cultures were fixed at room temperature for 25 min with $4 \%$ paraformaldehyde in $0.1 \mathrm{M}$ PBS (Euroclone) containing $0.12 \mathrm{M}$ sucrose. Cells were subsequently incubated for $20 \mathrm{~min}$ at room temperature with goat serum dilution buffer (GSDB) $(450 \mathrm{~mm} \mathrm{NaCl}$ and $20 \mathrm{~mm}$ sodium phosphate buffer, $\mathrm{pH} 7.4,15 \%$ goat serum, and $0.3 \%$ Triton X-100), before exposure to the primary antibodies diluted in GSDB. The following primary antibodies were used: rabbit anti-CGRP (1:800; Enzo Life Sciences AG), mouse anti- $\beta$-tubulin-III ( $\beta$-tubIII) (1: 500; Promega), mouse anti-glutamine synthetase (GS) (1:100; Millipore), mouse anti-vesicle-associated membrane protein 2 (VAMP2) (1: 300; Synaptic Systems). Bandeireae simplicifolia isolectin B4 directly conjugated to fluorescein isothiocyanate (FITC-IB4) (1:100; SigmaAldrich) was also used. After an overnight incubation at $4^{\circ} \mathrm{C}$, cells were rinsed three times for $10 \mathrm{~min}$ in a high-salt buffer solution $(500 \mathrm{mM} \mathrm{NaCl}$ and $20 \mathrm{~mm}$ sodium phosphate buffer, $\mathrm{pH} 7.4)$, and then incubated $(1 \mathrm{~h}$, room temperature) with secondary goat anti-rabbit and goat anti-mouse antibodies conjugated to Alexa Fluor 488 or Alexa Fluor 555 (1:600 in GSDB; Invitrogen). Subsequently, nuclei were labeled with the fluorescent dye Hoechst 33258 (1:10,000 in PBS, Invitrogen). Cells were rinsed three times in high-salt buffer, once in PBS, and finally once in $5 \mathrm{~mm}$ sodium phosphate buffer, $\mathrm{pH}$ 7.4. Coverslips were mounted with Fluorescent Mounting Medium (Dako), and analyzed using an inverted fluorescence microscope (200M; Zeiss) connected to a PC computer equipped with Axiovision software (Zeiss). Nonspecific staining was evaluated on sections where the primary antibodies were omitted from the staining procedure.

Immunohistochemistry. Mice were intraperitoneally anesthetized with $600 \mathrm{mg} / \mathrm{kg}$ chloral hydrate and transcardially perfused with $4 \%$ formalin fixative. Trigeminal ganglia (TGs) were then excised, postfixed in $4 \%$ formalin for $30 \mathrm{~min}$, and cryoprotected in $30 \%$ sucrose for at least $24 \mathrm{~h}$. Left and right ganglia from each animal were embedded together in mounting medium (Tissue-Tek O.C.T.; Sakura Finetek), and cut longitudinally on a cryostat at $10 \mu \mathrm{m}$ thickness. Sections were incubated for 45 min in PBS containing 10\% normal goat serum (Sigma-Aldrich) and $0.1 \%$ Triton X-100 (Sigma-Aldrich) and then overnight at room temperature with the primary antibodies listed above. Sections were then rinsed three times with PBS, and incubated for $1 \mathrm{~h}$ at room temperature with the Alexa Fluor 488- or Alexa Fluor 555-conjugated secondary antibodies (see above). All antibodies were diluted in PBS containing $0.1 \%$ Triton X-100 and 1\% normal goat serum. Samples were finally examined with a laser scanning confocal microscope (LSM 510, Zeiss), and images were acquired and analyzed using the LSM Image Browser software (Zeiss).

Intracellular calcium measurements. Cells grown onto $24 \mathrm{~mm}$ glass coverslips were loaded with $2 \mu \mathrm{M}$ Fura-2 pentacetoxy methyl ester (45 min at $37^{\circ} \mathrm{C}$ ) in Krebs-Ringer solution buffered with HEPES (in mM: 125 $\mathrm{NaCl}, 5 \mathrm{KCl}, 1.2 \mathrm{MgSO}_{4}, 2 \mathrm{CaCl}_{2}, 10$ glucose, and $25 \mathrm{HEPES} / \mathrm{NaOH}, \mathrm{pH}$ 7.4), and then transferred to the recording chamber of an inverted microscope (Axiovert 100TV; Zeiss) equipped with a calcium imaging unit. Polychrome IV (TILL Photonics) was used as light source. Fura-2 fluorescence images were collected with a CCD camera Imago-QE (TILL Photonics), and analyzed with the TILLvisION 4.0.1 software. After excitation at 340 and $380 \mathrm{~nm}$ wavelengths, the emitted light was acquired at $505 \mathrm{~nm}$ at $1 \mathrm{~Hz}$. Calcium concentrations were expressed as F340/380 fluorescence ratio. The ratio values in discrete areas of interest were calculated from sequences of images to obtain temporal analyses. Neurons were identified by their peculiar responsiveness to $50 \mathrm{~mm} \mathrm{KCl}$. The total number of cells analyzed for any given condition is indicated as " $n$." Calcium responses to acutely applied ADP ( $1 \mu \mathrm{M}$; Sigma-Aldrich), UTP ( 1 and $100 \mu \mathrm{M}$; Sigma-Aldrich), or CGRP $(1 \mu \mathrm{M})$ were analyzed.

Total RNA isolation and PCR analysis. Total RNA was extracted from freshly excised TGs or from cell cultures by using the TRIzol reagent 
(Invitrogen) following the manufacturer's instructions. DNase digestion, retrotranscription to CDNA and PCRs were performed as previously described (Bianco et al., 2005). Moreover, small pools of SGCs (from 2 up to 5 cells per sample) were sucked into a patch pipette by applying a negative pressure, and then processed for reverse transcriptase (RT)-PCR analysis, using oligo(dT) for retrotranscription. Choice of cells was done under light microscopy on the basis of their typical cell morphology (Fig. 1A; the yellow arrow indicates a representative SGC).

Specific primer pairs for the following cDNAs were used: mouse B1 receptor $(\mathrm{m} B d k r b 1$, sense 5' -TCCTGTCCTTCTTCCTTTTG-3', antisense 5'-CCATTGTCTTGCTGTCCTTG-3'), mouse $\mathrm{B} 2$ receptor $\left(\mathrm{mBdkrb2}\right.$, sense $5^{\prime}$-TTCACCAACGTGCTGCTGAAC-3', anti-sense 5' ACTGTTTCTTCCCTGCCCAGTC-3'), mouse receptor activity-modifying protein 1 (mRampl; sense 5'-GACGCTATGGTGTGACT-3', antisense 5'-AGTGCAGTCATGAGCAG-3'), mouse calcitonin receptor-like receptor ( $\mathrm{mCal}$ crl; sense 5'-TGCTGGAATGACGTTGCAGC3', anti-sense 5'-GCCTTCACAGAGCATCCAGA- $3^{\prime}$ ), and mouse glutamine synthetase (mGlul) (sense 5'-GCGACATGTACCTCCATCCT-3', anti-sense 5'-ACCCGATGCAAGATAAAACG- $3^{\prime}$ ). cDNA from each sample was also amplified with $\beta$-actin primers (sense 5'-TGACGGGGTCACCCACACTGTGCCCATCTA-3' , anti-sense 5' -CTAGAAGCATTGCGGTGGACGATGGAGGG-3') as an internal control. Primers were designed using the Oligo 4.0 primer analysis software. Amplifications were performed in a GeneAmp 9700 thermal cycler (Applied Biosystems) for 35-40 cycles (typically $94^{\circ} \mathrm{C} / 45 \mathrm{~s} ; 45 \mathrm{~s}$ at the optimal annealing temperature for each primer pair; $72^{\circ} \mathrm{C} / 45 \mathrm{~s}$ ), after an initial denaturation at $94^{\circ} \mathrm{C}$ for $2 \mathrm{~min}$.

Western blotting analysis. Whole-cell lysates were prepared and analyzed by Western blotting as previously described (Ceruti et al., 2008). Briefly, $\sim 30 \mu \mathrm{g}$ aliquots from each protein sample were loaded on $11 \%$ SDS-polyacrylamide gels and blotted onto nitrocellulose membranes (Bio-Rad). Filters were saturated with $10 \%$ nonfat dry milk in Tris-buffered saline (TBS) (1 mM Tris- $\mathrm{HCl}, 15 \mathrm{~mm} \mathrm{NaCl}, \mathrm{pH} 8$ ) for $1 \mathrm{~h}$ at room temperature, and then incubated overnight at $4^{\circ} \mathrm{C}$ with mouse anti-phospho-ERK1/2 (p-ERK1/2) and rabbit anti-ERK1/2 primary antibodies (1:500 and 1:1000, respectively, in 5\% nonfat dry milk in TBS; Cell Signaling Technology). Filters were then washed in TBS-T (TBS plus $0.1 \%$ Tween 20 ), incubated for $1 \mathrm{~h}$ with goat anti-rabbit or anti-mouse secondary antibody conjugated to horseradish peroxidase (1:4000 or 1:2000, respectively, in 5\% nonfat dry milk in TBS; SigmaAldrich). Detection of proteins was performed by ECL (GE Healthcare) and autoradiography. Nonspecific reactions were evaluated by performing immunoreactions in the presence of the secondary antibodies alone.

Analysis of CGRP release by enzyme immunoassay. Basal and stimulated extracellular CGRP concentrations were evaluated in primary mixed cultures after $48 \mathrm{~h}$ in vitro. Basal CGRP levels were measured after a $15 \mathrm{~min}$ incubation with fresh culture medium (see above), which was then removed, stored for subsequent analysis, and replaced with culture medium alone (CTR), or containing $100 \mathrm{~nm}$ BK. After a $1 \mathrm{~h}$ incubation at $37^{\circ} \mathrm{C}$, culture medium was collected. Maximal CGRP release was evaluated by a $15 \mathrm{~min}$ incubation with $50 \mathrm{~mm} \mathrm{KCl}$. All samples were finally centrifuged at $1200 \mathrm{rpm}$ for $5 \mathrm{~min}$, and the supernatants processed for CGRP measurement. A commercial Enzyme Immunometric Assay (EIA) kit for rat CGRP (SPIbio) was used, following the manufacturer's in- structions. We validated the use of this EIA kit for the measurements of mouse CGRP by verifying the homology between the mouse and rat mature $\alpha$-CGRP peptide sequences (UniProtKB database; www.uniprot.org), which was found to be $100 \%$. Samples were analyzed at a $415 \mathrm{~nm}$ wavelength with a microplate reader (iMark, Bio-Rad). CGRP concentrations in $\mathrm{pg} / \mathrm{ml}$ were extrapolated from a best-fit line calculated from serial dilutions of a CGRP sample standard.

Analysis of cytokine release. Cytokine release in culture media from purified SGC cultures was evaluated under CTR condition (i.e., samples exposed to Ham's F-12 medium alone) and after an overnight exposure to $1 \mu \mathrm{M}$ CGRP. At the end of the incubation, supernatants were collected and immediately processed. The commercial RayBio Mouse Cytokine Antibody Array-1 kit (RayBiotech, Inc) was used, following the manufacturer's instructions. This array allows the simultaneous detection of 22 different cytokines/chemokines and growth factors in the extracellular medium. After processing by chemiluminescent autoradiography, densitometric analysis of each spot was performed using the NIH ImageJ software. Data from CGRP-treated cultures are expressed as fold increase over control condition. For extracellular IL- $1 \beta$ measurement, a commercial ELISA kit (Mouse IL1 $\beta$ ELISA Kit, ThermoFisher Scientific) was used, following the manufacturer's instructions. Samples were analyzed at 450 and $550 \mathrm{~nm}$ wavelengths with a microplate reader, and values obtained at $550 \mathrm{~nm}$ were subtracted from values at $450 \mathrm{~nm}$ to correct for the optical imperfection of the plastic substrate. IL- $1 \beta$ concentrations (in $\mathrm{pg} / \mathrm{ml}$ ) were extrapolated from a standard curve generated with serial dilutions of an IL- $1 \beta$ standard (provided with the kit). 
A

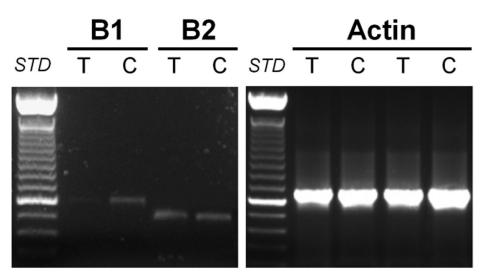

C

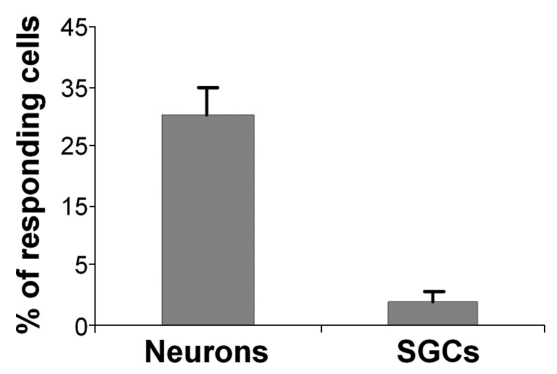

B

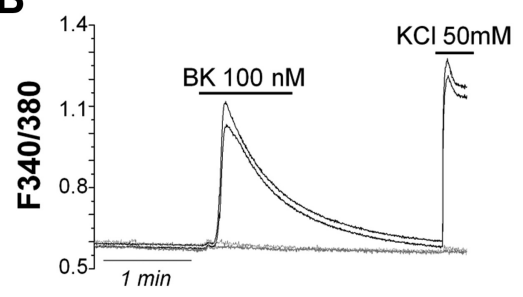

D

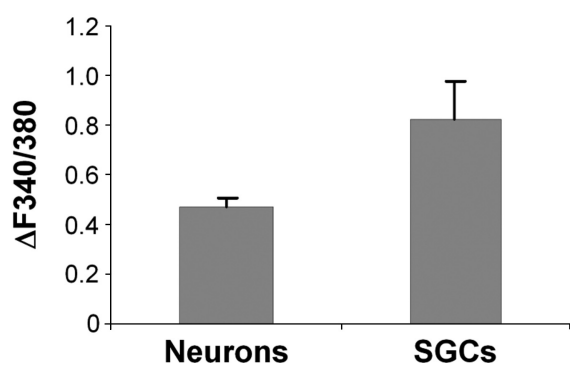

Figure 2. Trigeminal neurons in vitro express functional BK receptors. A, RT-PCR experiments demonstrating the expression of the mRNAs encoding for the B1 and B2 BK receptor subtypes (PCR product lengths: 600 and 508 bp, respectively) in intact trigeminal ganglia (T) and primary mixed trigeminal cultures $(C)$. The housekeeping gene $\beta$-actin (expected PCR product length, $661 \mathrm{bp}$ ) was used as an internal positive control. $\boldsymbol{B}$, Representative temporal plots of BK-evoked $\left[\mathrm{Ca}^{2+}\right]_{\mathrm{i}}$ increases in two trigeminal neurons (black lines), and two SGCs (gray lines). The depolarizing agent $\mathrm{KCl}(50 \mathrm{~mm})$ was used to discriminate between neurons (responding) and SGCS (nonresponding). C, D, Histograms showing the percentage of responding cells ( $\boldsymbol{C}$ ) and the mean calcium increases $(\boldsymbol{D})$ induced in neurons and SGCs by application of $100 \mathrm{~nm}$ BK. Data are the mean \pm SEM of 11 independent experiments.

Statistical analysis. All results are expressed as mean \pm SEM of at least three independent experiments. Statistical significance between groups was derived from one-way ANOVA followed by Scheffé's analysis, performed with the SPSS software for MacIntosh. Two degrees of significance were considered: $p<0.05$ or $p<0.01$.

\section{Results}

CGRP released from TG neurons upon BK application is responsible for $\mathrm{P} 2 \mathrm{Y}$ receptor upregulation in SGCs

Our experimental model consists of primary mixed TG cultures (Simonetti et al., 2006; Ceruti et al., 2008), whose typical appearance is shown in Figure 1A. The different cell populations have been identified based on their typical morphology. SGCs have a fusiform shape (see example pointed by the yellow arrow in Fig. $1 \mathrm{~A}$ ) and accounted for the $78.7 \%$ of the total cell number (Fig. $1 B$ ). Neurons (see red arrow in Fig. $1 A$ ) are larger spherical elements usually overlying other cell types, and make up $10 \%$ of the total cell population (Fig. $1 B)$. Finally, fibroblasts $(\sim 11 \%$; Fig. $1 B$ ) are flat, poorly visible elements under light microscopy, and with large elongated nucleus (Fig. $1 \mathrm{~A}$; see white arrow). Very few astrocytes and mature oligodendrocytes are normally detected in our cultures (Ceruti et al., 2008).

Unlike neurons and SGCs (Fig. 1C, red and yellow arrows, respectively), fibroblasts were excluded from single-cell calcium imaging analysis both based on their morphology, and on their inability to be loaded with the FURA-2 dye (Fig. 1C, white arrow). To confirm that the fusiform cells in culture were indeed SGCs, mRNA encoding for the typical marker GS was demonstrated in different pools of cells chosen on the basis of their fusiform morphology (from 2 to 5 cells/ each sample), and selectively picked up from primary culture coverslips (see Materials and Methods) (Fig. 1D).

We have previously demonstrated that a chronic (i.e., $24 \mathrm{~h}$ ) exposure of WT TG cultures to the proalgogenic mediator BK significantly enhances the responsiveness of glial P2Y receptors to their cognate ligands ADP and UTP (Ceruti et al., 2008). The reason for choosing a long period of incubation with BK was based on the observation that prolonged exposure of nociceptors to algogenic and proinflammatory mediators leads to neuronal and glial molecular changes, and contributes to the development of a chronic pathological pain state (Watkins and Maier, 2003). Following acute exposure to BK, indeed, no changes in glial P2Y receptormediated calcium responses were detected, unlike neuronal $\mathrm{P}_{2} \mathrm{X}_{3}$ receptor channels, which were significantly upregulated (Ceruti et al., 2008). To dissect the signaling pathways leading to P2Y receptor potentiation by BK, we first investigated the expression, function, and cellular localization of BK receptors (the B1 and B2 subtypes) in our cultures (Leeb-Lundberg et al., 2005). RT-PCR analysis demonstrated expression of the constitutive B2 receptor subtype in both the intact tissue and dissociated cultures (Fig. 2A). Conversely, the inducible B1 receptor subtype was barely present in intact tissue, and expressed in primary cultures, probably due to the time in culture (Fig. 2A). As expected (Ceruti et al., 2008), single-cell calcium imaging of primary mixed cultures revealed a predominant neuronal responsiveness to $100 \mathrm{~nm} \mathrm{BK}$ (Fig. $2 \mathrm{~B}, C$ ), with a mean calcium increase (evaluated as change in the $340 / 380$ fluorescence ratio; $\Delta F_{340 / 380}$ ) of $0.47 \pm 0.04$ (Fig. $2 D$ ). In addition to cell morphology criteria (see above), the application of $\mathrm{KCl}(50 \mathrm{~mm})$ was used to discriminate between neurons (responding) and SGCs (nonresponding). Only $\sim 4 \%$ of SGCs responded to BK application, with a mean $\Delta F_{340 / 380}$ of $0.83 \pm 0.15$ (Fig. 2C,D), whereas approximately one third of neurons were sensitive to BK (Fig. 2C,D). Thus, since these data clearly demonstrated that BK receptors were almost exclusively functional in TG neurons, we posited that a neuronal mediator released upon BK application should be responsible for the observed upregulation of glial P2Y receptor subtypes (Ceruti et al., 2008).

Data from literature suggest that CGRP is an important long-lasting migraine mediator (Ebersberger et al., 1999; Lassen et al., 2002; Meng et al., 2007). Therefore, we exposed the primary mixed wild-type TG cultures to BK alone or together with the CGRP receptor antagonist, $\mathrm{CGRP}_{8-37}$ for $24 \mathrm{~h}$, and subsequently recorded ADP- and UTP-induced increases in $\left[\mathrm{Ca}^{2+}\right]_{\mathrm{i}}$ in SGCs (Fig. 3). As expected, BK alone significantly increased the mean peak amplitudes (expressed as $\Delta F_{340 / 380}$ and normalized vs control cells exposed to the same $\mathrm{P} 2$ agonist set to 1.00$)$ evoked by $1 \mu \mathrm{M} \operatorname{ADP}(1.52 \pm 0.17, n=90$ cells from 3 independent experiments), or $10 \mu \mathrm{M} \mathrm{UTP}(1.53 \pm 0.18$, $n=71$ cells from 4 independent experiments). Pretreatment with $2 \mu \mathrm{M} \mathrm{CGRP}_{8-37}$ almost completely abolished the BKinduced effect (normalized $\Delta F_{340 / 380}: 1.10 \pm 0.08, n=172$ cells, and $1.11 \pm 0.12, n=95$ cells for ADP and UTP, respectively) (Fig. $3 A$ ). Moreover, a $24 \mathrm{~h}$ exposure to $1 \mu \mathrm{M}$ CGRP induced an increase in $\mathrm{P} 2 \mathrm{Y}$ receptor-mediated responses in SGCs as well (normalized $\Delta F_{340 / 380}: 1.56 \pm 0.11, n=146$ cells and $1.58 \pm 0.12, n=121$ cells for ADP and UTP, respectively; 4 independent experiments), which is in line with the BK- 

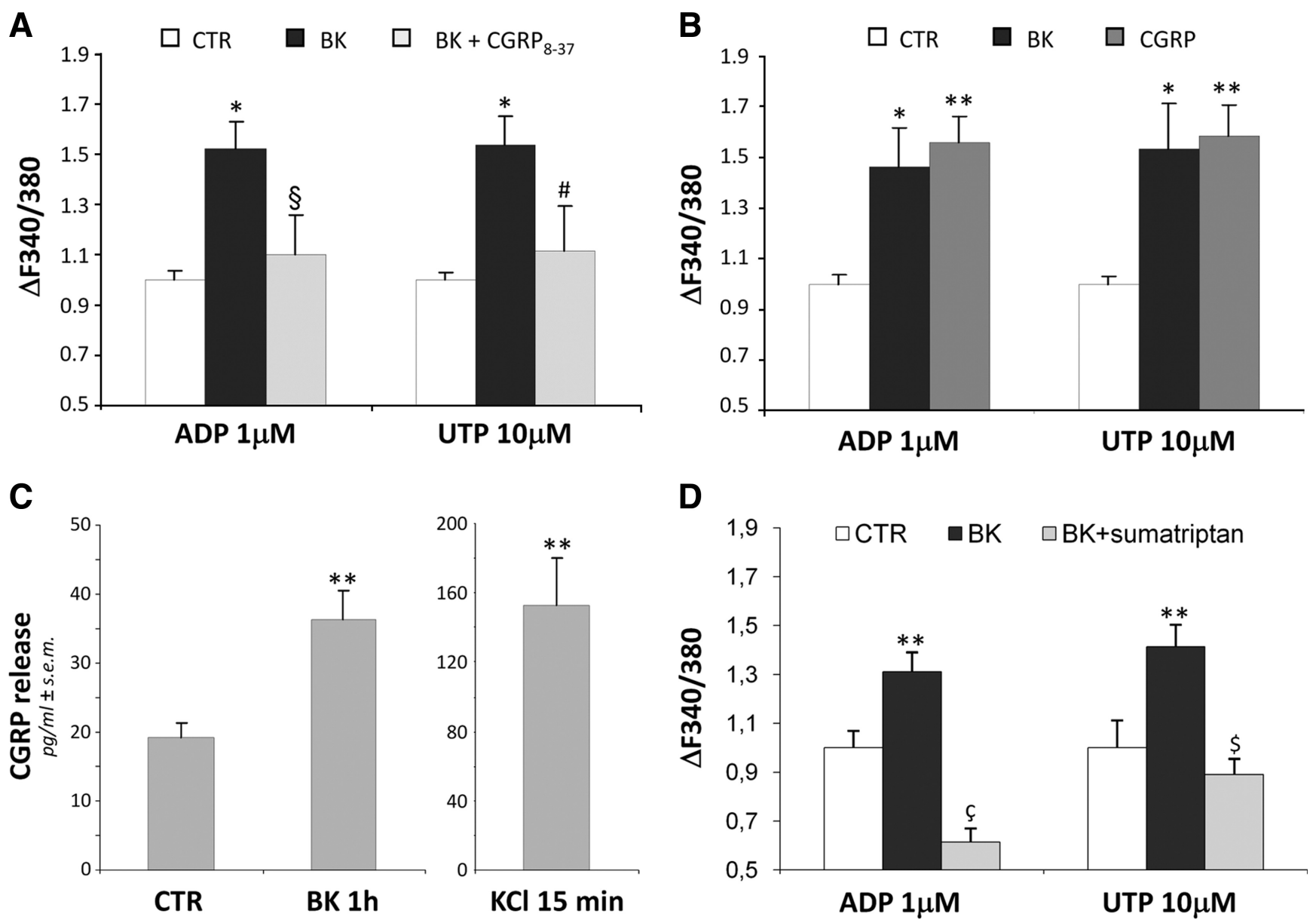

Figure 3. BK-induced enhancement of P2Y receptor function in trigeminal SGCS is mediated by CGRP. A, Primary mixed trigeminal cultures were subchronically ( $24 \mathrm{~h}$ ) treated with vehicle (CTR), or $100 \mathrm{~nm}$ BK alone and in the presence of the CGRP receptor antagonist GRPP $_{8-37}(2 \mu \mathrm{m})$. Cultures were then challenged with $1 \mu \mathrm{m} \mathrm{ADP}$ or $10 \mu \mathrm{m}$ UTP, and the increases in $\left[\mathrm{Ca}^{2+}\right]_{\mathrm{i}}$ recorded from SGCs. ${ }^{*} p<0.05$ with respect to $\mathrm{CTR} ;{ }^{\S} p<0.05$, and ${ }^{\#} p=0.057$ with respect to BK alone. B, Primary mixed trigeminal cultures were treated for $24 \mathrm{~h}$ with vehicle (CTR), $100 \mathrm{~nm} \mathrm{BK}$, or $1 \mu \mathrm{M}$ (GRP, then exposed to ADP or UTP, and changes in $\left[\mathrm{Ca}^{2+}\right]_{\mathrm{i}}$ analyzed in SGCs (see above). ${ }^{*} p<0.05$, and ${ }^{* *} p<0.01$ with respect to CTR. C, Histograms show the mean extracellular CGRP concentrations after $1 \mathrm{~h}$ application to primary mixed trigeminal cultures of either vehicle (CTR) or $100 \mathrm{~nm}$ BK. A $15 \mathrm{~min}$ exposure to $50 \mathrm{~mm}$ KCl was used as a positive control of maximal neuronal CGRP release. ${ }^{* *} p<0.01$ with respect to CTR. D, Primary mixed trigeminal cultures were treated for $24 \mathrm{~h}$ with vehicle (CTR) or $100 \mathrm{~nm}$ BK alone and in the presence of sumatriptan $(10 \mu \mathrm{M})$. Cultures were then exposed to ADP or UTP, and changes in $\left[\mathrm{Ca}^{2+}\right]_{\mathrm{i}}$ analyzed in SGCs (see above). ${ }^{* *} p<0.01$ with respect to $C$ TR; ${ }^{{ }^{c}} p<0.01$ with respect to both CTR and BK alone; ${ }^{5} p<0.01$ with respect to BK alone. In $\boldsymbol{A}, \boldsymbol{B}$, and $\boldsymbol{D}$, histograms show the mean $\left[\mathrm{Ca}^{2+}\right]_{i}$ normalized to $\mathrm{CTR}$ cells set to 1.0 from at least 3 independent experiments. Statistical analysis was performed by one-way ANOVA followed by Scheffé's test.

induced effect being CGRP dependent (normalized $\Delta F_{340 / 380}$ : $1.46 \pm 0.16, n=108$ cells, and $1.53 \pm 0.18, n=71$ cells for ADP and UTP, respectively; 4 independent experiments) (Fig. $3 B$ ). No changes in the percentages of responding SGCs were observed after either treatment (data not shown).

Next we measured extracellular CGRP concentrations after application of BK. As shown in Figure $3 C$, a $1 \mathrm{~h}$ treatment of primary mixed TG cultures with $100 \mathrm{~nm}$ BK almost doubled extracellular CGRP levels from $19.10 \pm 2.28 \mathrm{pg} / \mathrm{ml}$ ( $n=22$ coverslips from 6 independent experiments) in CTR cultures, to $36.33 \pm 4.07 \mathrm{pg} / \mathrm{ml}$ ( $n=23$ coverslips $)$ in BK-treated cultures. The maximal CGRP release was assessed by exposing cultures to $50 \mathrm{~mm} \mathrm{KCl}$ for $15 \mathrm{~min}$, and corresponded to $152.5 \pm 27.51 \mathrm{pg} / \mathrm{ml}$ ( $n=21$ coverslips). Finally, a $30 \mathrm{~min}$ pretreatment of cultures with the anti-migraine drug sumatriptan, a serotonin agonist, which was shown to inhibit CGRP release from TG neurons (Durham and Russo, 2002), completely prevented BK-induced potentiation of $\mathrm{P} 2 \mathrm{Y}$ receptor function to values even lower than basal ones (normalized $\Delta F_{340 / 380}: 0.61 \pm 0.06, n=43$ cells, and $0.89 \pm 0.06, n=54$ cells for ADP and UTP, respectively, in samples treated with $\mathrm{BK}+$ sumatriptan; 2 independent experi- ments) (Fig. 3D). This latter observation suggested to us that, at least for ADP-sensitive P2Y receptor subtypes on SGCs, there is a constitutive modulation by neuronally released factors under basal conditions. Overall, these results indicate an important role for CGRP as the key mediator of neuron-to-SGC communication upon BK exposure.

CGRP is selectively expressed by TG neurons, while SGCs express CGRP receptors functionally coupled to modulation of $\left[\mathrm{Ca}^{2+}\right]_{i}$

Our results clearly demonstrate that exposure of primary mixed TG cultures to BK evokes a significant extracellular CGRP release. Data from literature (Xiao et al., 2008) and our data on maximal CGRP release evoked by the depolarizing agent $\mathrm{KCl}$ (see above; Fig. 3C) already suggested a neuronal localization and release of this neuropeptide. To unequivocally confirm this, we performed double immunofluorescence experiments with an anti-CGRP antibody and various cell-specific markers. First of all, in intact ganglia, CGRP was expressed by $34.2 \pm 0.80 \%$ of $\beta$-tubIIIpositive neurons $(n=3,251)$ (Fig. $4 A$ ). To some extent there was colocalization of CGRP with isolectin B4 (IB4), a marker of sen- 

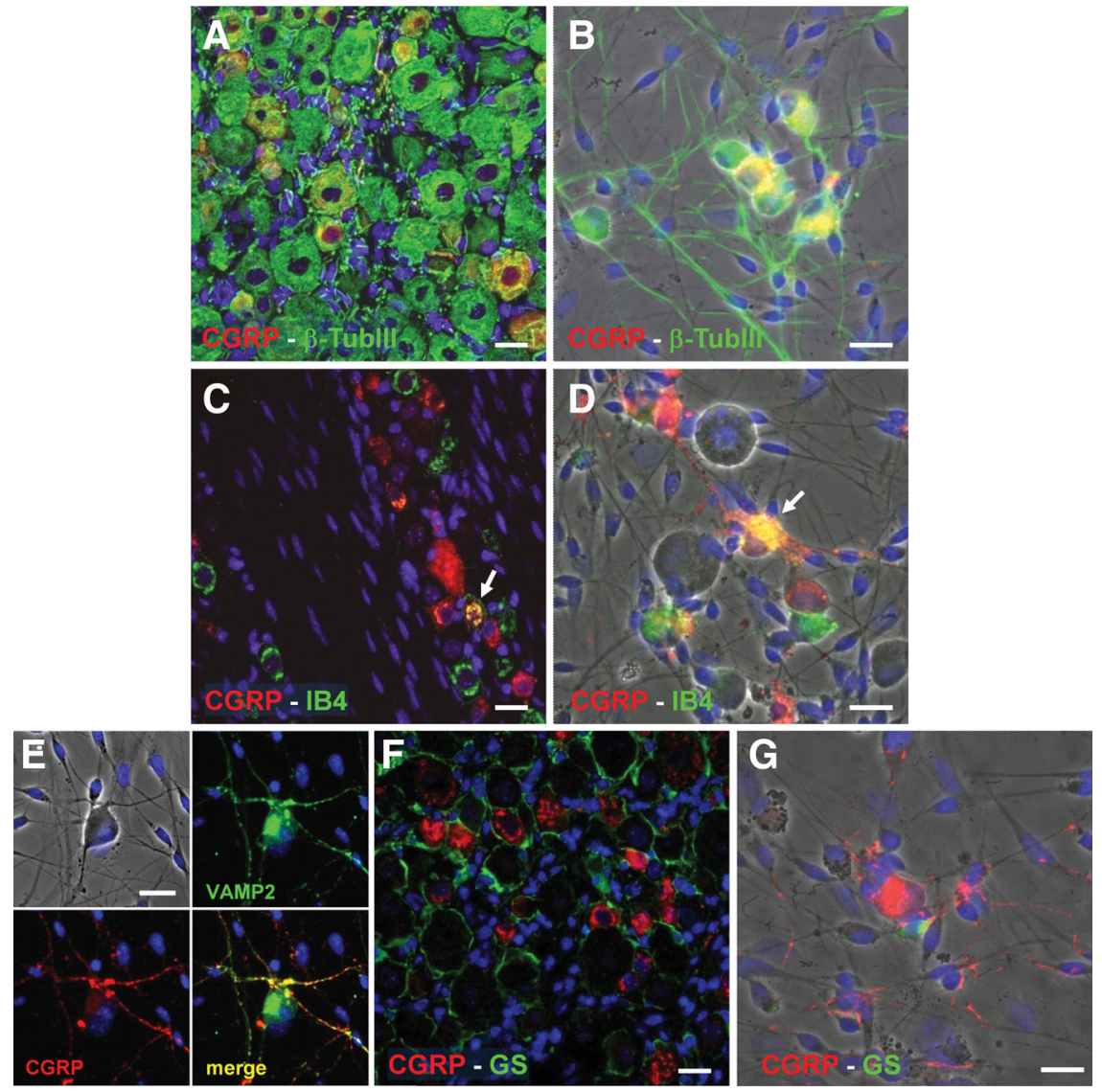

Figure 4. Trigeminal neurons selectively express CGRP both ex vivo and in vitro. $\boldsymbol{A}, \boldsymbol{B}$, Double immunofluorescence staining of the CGRP peptide (red) and of the neuronal marker $\beta$-tublll (green) in intact trigeminal ganglia $(\boldsymbol{A})$ and in primary mixed trigeminal cultures after $48 \mathrm{~h}$ in vitro $(\boldsymbol{B}) . \boldsymbol{C}, \boldsymbol{D}$, Double immunofluorescence staining of the CGRP peptide (red) and FITC-conjugated IB4 (green), taken here as a marker of sensory neurons, in intact trigeminal ganglia $(\boldsymbol{C})$ and in primary mixed trigeminal cultures after $48 \mathrm{~h}$ in vitro $(\boldsymbol{D})$. Arrows indicate colocalization. $\boldsymbol{E}$, Specific localization of CGRP (red) to VAMP2-positive axons terminals (green) in primary trigeminal cultures. $\boldsymbol{F}, \mathbf{G}$, CGRP (red) never colocalizes with the SGC marker GS (green). In all pictures, nuclei were labeled with the Hoechst 33258 dye (blue). Scale bars, $20 \mu \mathrm{m}$. sory neurons $(4.5 \pm 0.98 \%, n=690$ of CGRP-positive neurons were also IB4positive) (Fig. 4C). We did not observe any substantial difference in CGRP colocalization with IB4 between the three major divisions of the TG [i.e., the ophthalmic (V1), maxillary (V2), and mandibular (V3) divisions; data not shown]. Interestingly, primary mixed TG cultures retained the neuronal location of CGRP observed in the intact tissue (CGRP colocalization with $\beta$-tubIII: $35.0 \pm 1.85 \%, n=588$; CGRP colocalization with IB4: $3.1 \pm 0.59 \%, n=371$ ) (Fig. $4 B, D)$. Indeed, CGRP was specifically localized to VAMP2-positive axons terminals (Fig. $4 E$ ). Finally, no expression of CGRP in GS-positive SGCs was seen in either intact TG or dissociated cultures (Fig. $4 F, G$ ). Together, these results confirm the exclusive neuronal localization of CGRP (Li et al., 2008).

Both TG neurons and SGCs express the CGRP receptor complex, although to a different extent (Lennerz et al., 2008). The primary transduction mechanism activated by CGRP receptors is via adenylyl cyclase, though coupling to phospholipase $\mathrm{C}$ with consequent rise in intracellular calcium has also been shown (Buldyrev et al., 2006). To determine whether CGRP could directly activate SGCs, and whether intracellular calcium was involved, we acutely applied $1 \mu \mathrm{M}$ CGRP to primary mixed TG cultures, and observed a calcium increase in $24.3 \pm$ $4.3 \%$ of SGCs $(n=24$ cells from 2 independent experiments). As previously reported (Fabbretti et al., 2006), neurons showed no increase in their $\left[\mathrm{Ca}^{2+}\right]_{\mathrm{i}}$ after acute CGRP exposure ( $n=20$ cells from 2 independent experiments) (Fig. 5), suggesting that the predominant second messenger system in neurons is likely represented by adenylyl cyclase. Nevertheless, our data show that phospholipase C-coupled CGRP receptors are functional on SGCs in mixed TG cultures.

\section{CGRP, but not $\mathrm{BK}$, retains its ability to induce $\mathrm{P} 2 \mathrm{Y}$ receptor potentiation in purified SGC cultures}

To get further insights in the molecular pathways linking glial CGRP receptor activation to the upregulation of $\mathrm{P} 2 \mathrm{Y}$ receptor function, we generated an in vitro model of purified SGC cultures. With our culture protocol, $79.3 \pm 1.84 \%$ of the total number of cells was identified as SCGs (based on the same criteria used for mixed cultures; see above), with fibroblasts accounting for the remaining $20.7 \pm 1.84 \%$ ( $n=4$ independent coverslips). Fibroblasts were again excluded from single-cell calcium imaging (see above). First, we demonstrated that there is no difference in $\mathrm{P} 2 \mathrm{Y}$ receptor expression and function between purified SGC cultures and primary mixed neuron-glia cultures at day 2 in vitro (Villa et al., 2010). RT-PCR analysis of the mRNAs encoding for two subunits composing the functional CGRP receptor [namely, receptor activity-modifying protein 1 (RAMP1), and calcitonin receptor-like receptor (CLR)] (Lennerz et al., 2008) showed that

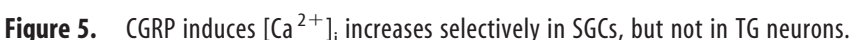
Representative temporal plot of $\left[\mathrm{Ca}^{2+}\right]_{\mathrm{i}}$ changes recorded from a SGC (black line) and a neuron (gray line) upon a $1 \mu \mathrm{m}$ (GRP challenge, followed by $50 \mathrm{~mm} \mathrm{KCl}$ application. Neurons were insensitive to the application of the neuropeptide $(n=20)$. 
the expression of CGRP receptor complex was retained in purified SGC cultures (Fig. 6A).

Next, we exposed purified SGC cultures to $100 \mathrm{nM}$ BK and $1 \mu \mathrm{M}$ CGRP for $24 \mathrm{~h}$, and analyzed the mean $\left[\mathrm{Ca}^{2+}\right]_{\mathrm{i}}$ responses after ADP and UTP application. Differently from mixed neuron-SGC cultures (see above; Fig. 3), P2Y receptor function in purified glial cultures was unaffected by BK application (normalized $\Delta F_{340 / 380}: 0.98 \pm 0.15, n=174$ cells from 3 independent experiments, and $0.92 \pm$ $0.18, n=99$ cells from 2 independent experiments, after exposure to $1 \mu \mathrm{M}$ ADP and $100 \mu \mathrm{M}$ UTP, respectively) (Fig. $6 B$ ). Conversely, CGRP retained its ability to potentiate glial $\mathrm{P} 2 \mathrm{Y}$ receptors even in the absence of neurons (normalized $\Delta F_{340 / 380}$ : $1.42 \pm 0.11, n=366$ cells from 4 independent experiments, and $1.48 \pm 0.14, n=150$ cells from 3 independent experiments, in the case of ADP and UTP, respectively) (Fig. 6B-D). Globally, these data further demonstrated that BK did not directly target SGCs, but rather acts via its neuronal receptors, and that the mediator of this neuronal-to-glial cell communication is indeed CGRP.

\section{Exposure of SGCs to CGRP induces}

extracellular release of several pro- and anti-inflammatory mediators

A complex network of pro- and anti-inflammatory molecules is believed to play a key role in the communication between neurons and SGCs within the TG, and is crucially involved in the development of TG sensitization (Hanani, 2005). Since it is known that CGRP can modulate cytokine release from SGCs (Thalakoti et al., 2007; Vause and Durham, 2010), we investigated changes in the extracellular level of 23 immunomodulatory molecules (see Materials and Methods). Overnight exposure to 1 $\mu \mathrm{M}$ CGRP significantly modulated the release of 12 of 23 cytokines by at least 1.5-fold (Table 1 ). The vast majority of both proand anti-inflammatory mediators was upregulated, with only proinflammatory IL-17 and IFN- $\gamma$ levels being reduced. These results show that exposure to CGRP produced an extracellular immunomodulatory milieu, which could possibly participate to the development of migraine pain and trigeminal sensitization.

\section{The ERK1/2 MAP kinase pathway has a primary role in CGRP-induced effects}

Since it is well known that CGRP activates the MAP kinase pathway in TG SGCs (Vause and Durham, 2009, 2010), we exposed purified WT SGC cultures to $1 \mu \mathrm{M}$ CGRP and analyzed the phosphorylation/activation of the three MAP kinase pathways [namely, ERK1/2, p38, and c-Jun N-terminal protein kinase (JNK)] by Western blotting. Basal activation of both p38 and JNK was detected at each time point tested, with no further increase elicited by CGRP exposure (data not shown). These results suggested that neither p38 nor JNK MAP kinases were directly involved in our experimental paradigm. Conversely, $1 \mu \mathrm{M}$ CGRP induced a complex activation of ERK1/2 (measured as the ratio between the intensities of the phosphorylated vs total ERK1/2
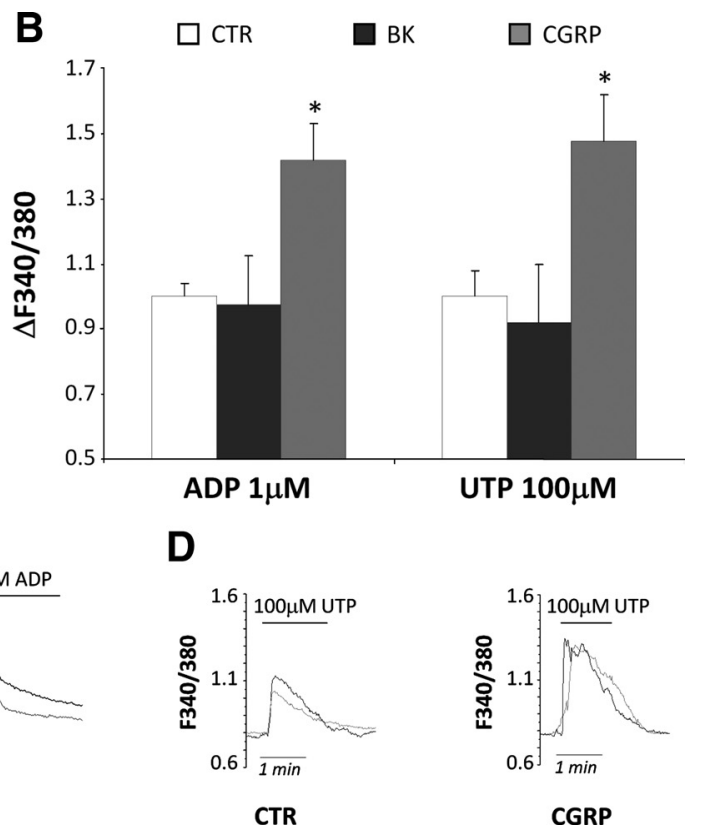

CGRP

D
CGRP

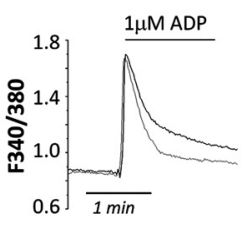

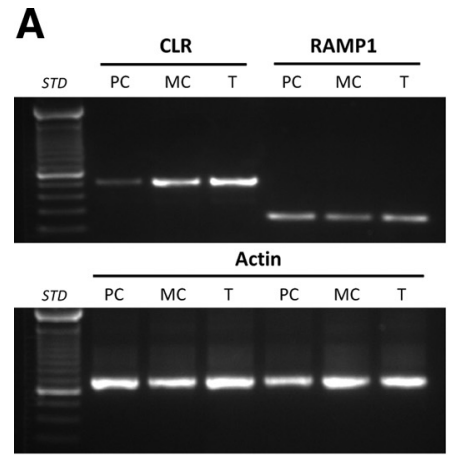

CTR
Figure 6. $\quad$ CGRP, but not $B K$, maintains its ability to potentiate $P 2 Y$ receptors responsiveness in purified SGC cultures. $A, R T-P C R$ 政 $\left.{ }^{2+}\right]_{i}$ increases recorded from purified SGC cultures after a $24 \mathrm{~h}$ treatment with either (CTR), $100 \mathrm{~nm} \mathrm{BK}$, or $1 \mu \mathrm{m}$ CGRP. Mean $\left[\mathrm{Ca}^{2+}\right]_{i}$ values have been normalized to CTR set to 1.0. C, D, Representative plots showing the increased ADP-and UTP-induced $\left[\mathrm{Ca}^{2+}\right]_{i}$ peaks in SGCs after chronic exposure to CGRP compared with CTR. ${ }^{*} p<0.05$ with respect to CTR; one-way ANOVA followed by Scheffé's test.

Table 1. Average fold change in release of cytokines from SGC-purified cultures following overnight exposure to CGRP (1 $\mu \mathrm{M})$

\begin{tabular}{llc}
\hline & \multicolumn{2}{l}{ CGRP-treated cultures } \\
\cline { 2 - 3 } & Average fold change over control cultures & \pm SEM \\
\hline IL-12_P40P70 & 19.18 & 8.36 \\
IL-3 & 12.35 & 2.89 \\
IL-2 & 12.29 & 6.49 \\
SCF & 11.11 & 4.93 \\
GCSF & 5.72 & 0.98 \\
IL-10 & 5.47 & 3.27 \\
IL-13 & 1.95 & 0.46 \\
GM-CSF & 1.83 & 0.17 \\
IL-1 $\beta$ & 1.50 & 0.17 \\
IL-12_P70 & 1.49 & 0.24 \\
IL-17 & 0.64 & 0.10 \\
IFN $\gamma$ & 0.43 & 0.10 \\
\hline
\end{tabular}

Cytokine release was evaluated in culture supernatants by means of the RayBio Rat Cytokine Antibody Array, with the only exception being IL-1 $\beta$ release, measured with ELISA. Only cytokines whose extracellular levels were significantly increased or decreased by (GRP treatment are shown (11 of 22 cytokines in the array). No significant changes were observed in IL-4, IL-5, IL-6, IL-9, monocyte chemoattractant protein-1 (MCP1), MCP5, Rantes, soluble tumor necrosis factor receptor I, tumor necrosis factor- $\alpha$, thrombospondin, and vascular endothelial growth factor concentrations. Results are the mean \pm SEM of 4 independent experiments. GM-CSF, Granulocyte-macrophage colony-stimulating factor; GCSF, granulocyte colony-stimulating factor; SCF, stem cell factor.

protein bands) with two peaks at 10 and $40 \mathrm{~min}$ (ratio phospho/ total ERK1/2: $4.17 \pm 1.19$ and $4.70 \pm 1.20$ at 10 and $40 \mathrm{~min}$, respectively. ${ }^{*} p<0.05$ with respect to corresponding control, one-way ANOVA followed by Scheffé's test), followed by a sustained delayed increment (Fig. 7A). ERK1/2 activation was completely inhibited by the CGRP receptor antagonist $\mathrm{CGRP}_{8-37}$ (Fig. $7 B)$. Noteworthy, the ERK1/2 pathway appeared to be directly correlated with the potentiation of $\mathrm{P} 2 \mathrm{Y}$ receptors function, since its inhibitor PD98059 fully prevented the increase in UTPmediated calcium mobilization induced by CGRP (normalized 
A
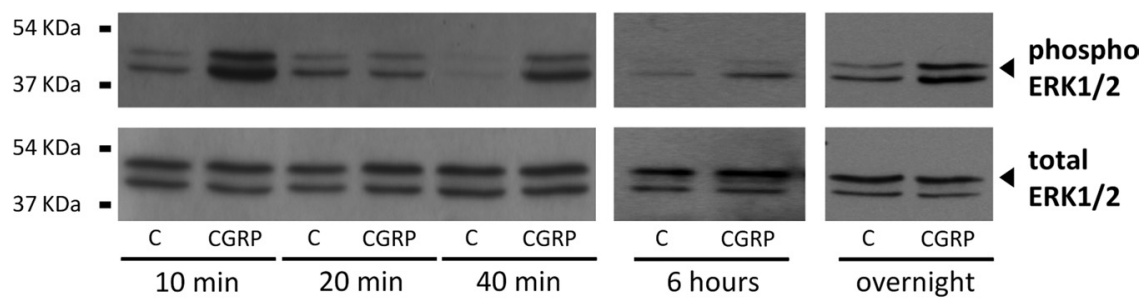

B

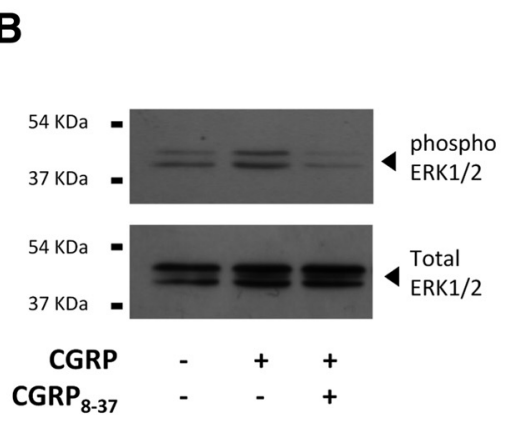

\begin{abstract}
C
\end{abstract}

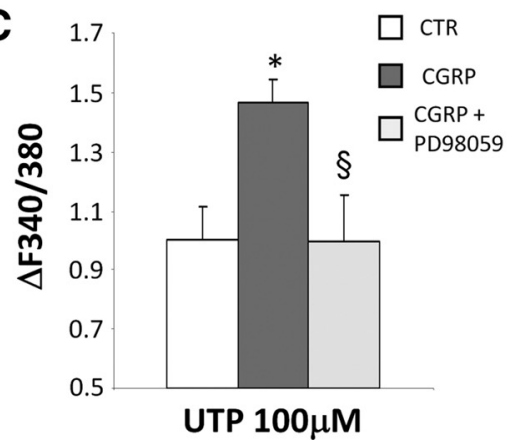

Figure 7. CGRP-induced P2Y receptor upregulation involves the ERK1/2 MAP kinase pathway. $\boldsymbol{A}$, Representative Western blotting experiment showing the time-dependent activation of ERK1/2 induced by application of $1 \mu \mathrm{M}$ CGRP for 10, 20 and $40 \mathrm{~min}$, $6 \mathrm{~h}$ and overnight to purified SGC cultures. $\boldsymbol{B}$, The CGRP receptor antagonist $\mathrm{CGRP}_{8-37}(2 \mu \mathrm{m})$ inhibits CGRP-induced ERK1/2 activation (10 min). C, The ERK1/2 inhibitor PD98059 prevents the potentiation of UTP-evoked [ $\left.\mathrm{Ca}^{2+}\right]_{\mathrm{i}}$ increases induced by CGRP. Histograms show the mean calcium increases in SGCs after chronic (24h) treatment with vehicle (CTR), $1 \mu \mathrm{m}$ CGRP alone, or CGRP $+50 \mu \mathrm{M}$ PD98059. In C, data are the mean \pm SEM of 3 independent experiments. ${ }^{*} p<0.05$ with respect to $C T R,{ }^{\S} p<0.05$ with respect to cells treated with CGRP alone; one-way ANOVA followed by Scheffé's test.

$\Delta F_{340 / 380}: 1.46 \pm 0.08, n=63$ cells from 2 independent experiments for CGRP alone, and $0.99 \pm 0.16, n=40$ for CGRP + PD98059) (Fig. 7C).

\section{CGRP release is significantly enhanced in TG cultures from} $\mathrm{Ca}_{\mathrm{V}} 2.1 \alpha 1 \mathrm{R} 192 \mathrm{Q}$ mutant knock-in mice

Our data point to a key role of CGRP in the communication between TG neurons and SGCs, contributing to the molecular and signaling network controlling the transmission and integration of painful signals. To further investigate this, we decided to evaluate both basal and stimulated CGRP release from primary TG cultures obtained from a transgenic mouse model of migraine (the $\mathrm{Ca}_{\mathrm{V}} 2.1 \alpha 1 \mathrm{R} 192 \mathrm{Q}$ mutant KI mouse) (van den Maagdenberg et al., 2004). Figure $8 \mathrm{~A}$ shows that, under basal conditions, a significantly higher $(45.9 \%)$ CGRP release was detected in primary TG cultures from KI mice $(50.49 \pm 7.33 \mathrm{pg} / \mathrm{ml}, n=29$ coverslips from 3 independent experiments) with respect to WT cultures $(34.60 \pm 2.76 \mathrm{pg} / \mathrm{ml}, n=30$ coverslips from 3 independent experiments). This effect was not due to a higher number of neurons in the KI cultures, since the mean number of neuronal cells did not differ between WT and KI cultures (100.4 $\pm 11.20 \mathrm{vs}$ $81.00 \pm 21.04$ neurons in identical areas of coverslips from WT and KI cultures, respectively; $n=6$, not statistically different). Following exposure to $100 \mathrm{~nm} \mathrm{BK}(1 \mathrm{~h})$, CGRP extracellular levels increased, but more in KI cultures, with CGRP levels of $64.83 \pm 6.30 \mathrm{pg} / \mathrm{ml}$ in WT cultures ( $n=13$ coverslips from 3 independent experiments), and $110.80 \pm 19.70 \mathrm{pg} / \mathrm{ml}(n=10$ coverslips) in KI cultures (Fig. $8 B$ ). A more than twofold (238\%) higher CGRP release was detected in $\mathrm{KI}$ with respect to WT cultures after maximal neuronal depolarization by $50 \mathrm{~mm} \mathrm{KCl} \mathrm{(15} \mathrm{min)} \mathrm{either} \mathrm{(from} 194.1 \pm 28.25 \mathrm{pg} / \mathrm{ml}, n=9$ coverslips from 3 independent experiments, to $461.1 \pm 119.2 \mathrm{pg} / \mathrm{ml}, n=8$ coverslips in WT and KI cultures, respectively, corresponding to 4.13- and 7.03-fold over basal value in WT and KI cultures, respectively) (Fig. $8 \mathrm{~B}$ ).

\section{In TG cultures from KI mice, exposure to BK not only increased P2Y-mediated calcium responses in SGCs, but also significantly enhanced the percentage of responding cells}

Since our data on WT cultures propose a modulation of the purinergic system by proalgogenic molecules like $\mathrm{BK}$ and CGRP, based on the finding that higher extracellular CGRP concentrations were present in cultures from KI mice, we deemed it interesting to evaluate $\mathrm{P} 2 \mathrm{Y}$ receptor function after exposure to BK also in these cultures. No difference in ADPand UTP-mediated calcium responses between WT and KI cultures under basal conditions was observed. Moreover, the potentiating effect of $\mathrm{BK}$ on $\mathrm{P} 2 \mathrm{Y}$ receptor activity tested with ADP or UTP was maintained in KI cultures to a similar extent to what observed in WT cultures (Fig. $8 C, D)$. Nonetheless, in KI cultures a significant increase in the percentage of UTP-responding cells was detected after exposure to BK $(20.09 \pm 2.71$ in WT vs $54.85 \pm 1.15$ in KI cultures; $+173 \%$ with respect to WT), corresponding to $+82.9 \%$ with respect to untreated KI cultures (Fig. $8 E, F)$. Likewise, an increased number of responding cells was also observed with $\mathrm{ADP}(55.6 \pm 7.42$ in BK-treated WT cultures vs $75.7 \pm 3.63$ in BK-treated KI cultures; $\left.{ }^{\$} p<0.05\right)$. Together, these results suggest that in KI cultures there is an overactivation of the purinergic neuron-to-glia crosstalk following exposure to proinflammatory and proalgogenic stimuli, which might have important implications in the development and maintenance of migraine pain.

\section{Discussion}

The main findings of our paper are as follows: (1) application of BK to primary WT TG cultures evokes CGRP release from neurons; (2) CGRP activates its receptors on neighboring SGCs leading to the activation/recruitment of ERK1/2, subsequent potentiation of P2Y-mediated responses in SGCs, and release of pro- and anti-inflammatory cytokines; (3) higher basal and stimulated CGRP release is detected in TG cultures of $\mathrm{Ca}_{\mathrm{V}} 2.1 \alpha 1 \mathrm{R} 192 \mathrm{Q}$ mutant KI mice, a transgenic mouse model of hemiplegic migraine; (4) BK not only potentiates P2Y-mediated responses, but also augments the percentage of glial responding cells in KI culture.

Our results are the first demonstration that the activity of $G$ protein-coupled $\mathrm{P} 2 \mathrm{Y}$ receptors of glial cells can be modulated by CGRP in TGs, raising the possibility that P2Y receptors might be involved in the peripheral TG sensitization occurring during (and between) migraine attacks (for a schematic view, see Fig. 9). Reversal of $\mathrm{P} 2 \mathrm{Y}$ receptor potentiation by the anti-migraine drug sumatriptan, known to inhibit CGRP release from TG neurons (Durham and Russo, 2002), further supports this hypothesis. Our results obtained in cultures from KI mice suggest that the complex interplay between TG neurons and SCGs could become even more important under pathological conditions.

Glial cells are taking the center stage in the search for new and effective therapies for acute and chronic pain states. Activated 


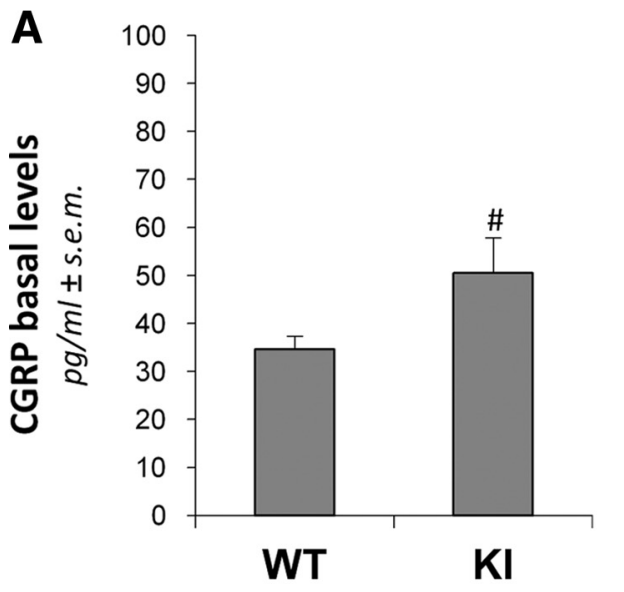

C
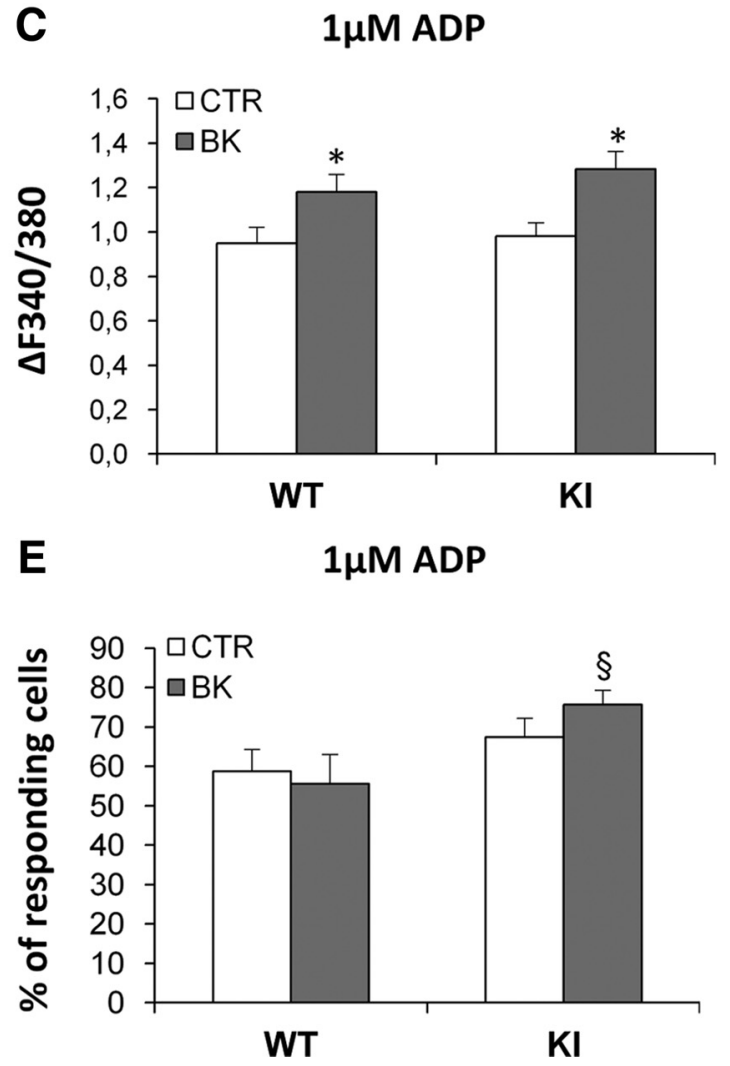
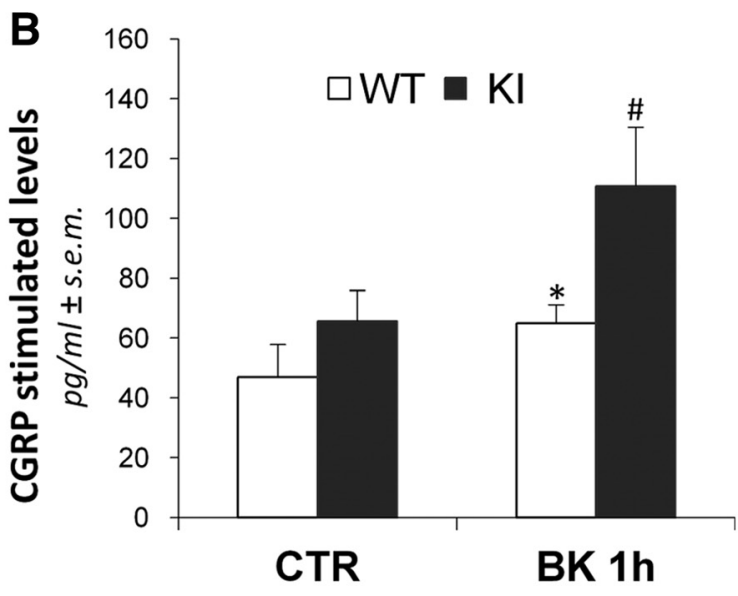

D

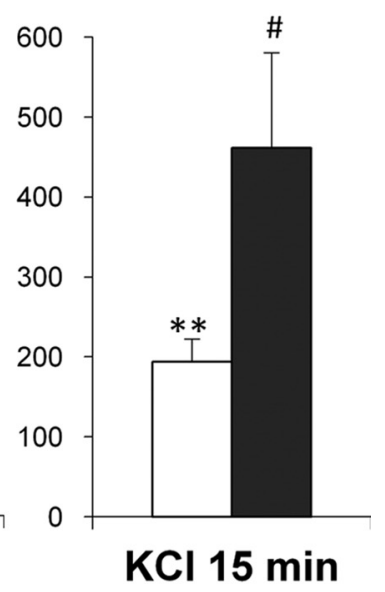

$10 \mu \mathrm{M}$ UTP

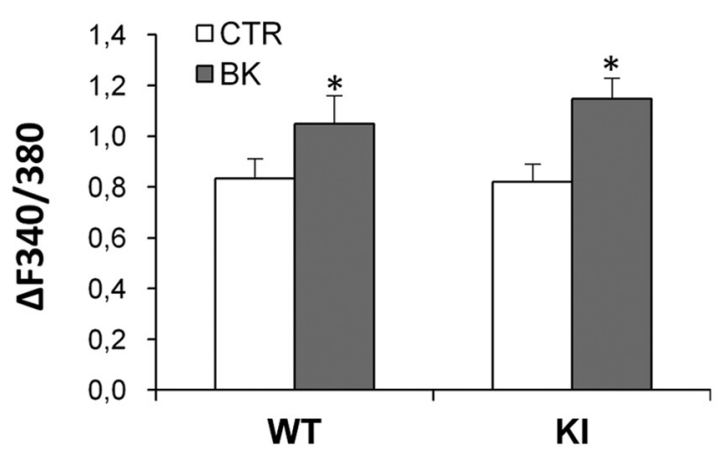

F

$10 \mu \mathrm{M}$ UTP

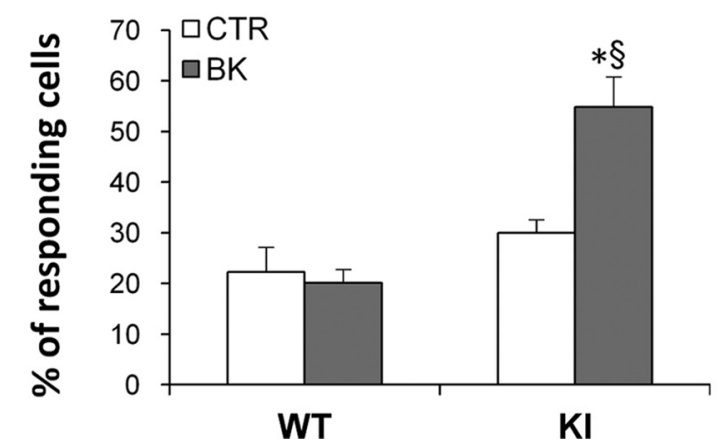

Figure 8. In trigeminal cultures from C $\mathrm{a}_{\mathrm{v}} 2.1 \alpha 1 \mathrm{R} 1920$ mutant KI mice (KI), a genetic mouse model of hemiplegic migraine, higher basal and stimulated extracellular CGRP concentrations and a BK-induced upregulation of glial P2Y receptors are observed. $\boldsymbol{A}, \boldsymbol{B}$, Histograms show the mean extracellular CGRP levels in primary mixed trigeminal cultures from WT and KI mice, after $48 \mathrm{~h}$ in vitro. Basal CGRP concentrations were measured after a 15 min incubation with fresh medium alone $(\boldsymbol{A})$, whereas stimulated CGRP levels were measured after a subsequent incubation with vehicle (CTR; $1 \mathrm{~h}), 100 \mathrm{~nm} \mathrm{BK}(1 \mathrm{~h})$, or $50 \mathrm{~mm} \mathrm{KCl}(15 \mathrm{~min})(\boldsymbol{B}) . \boldsymbol{C}-\boldsymbol{F}$, Histograms show the mean $\left[\mathrm{Ca}^{2+}\right]_{\mathrm{i}}$ increases elicited by $1 \mu \mathrm{m}$ ADP or $10 \mu \mathrm{m}$ UTP $(\boldsymbol{C}, \boldsymbol{D})$, and the mean percentage of responding cells $(\boldsymbol{E}, \boldsymbol{F})$ in WT and KI cultures, after a $24 \mathrm{~h}$ treatment with vehicle alone (CTR) or with $100 \mathrm{~nm} \mathrm{BK.}{ }^{*} p<0.05$, and ${ }^{* *} p<0.01$ with respect to the corresponding WT or KI control; \# $p<0.05$ with respect to CGRP levels in WT cultures; ${ }^{\S} p<0.05$ with respect to WT cultures exposed to BK; one-way ANOVA followed by Scheffé's analysis.

astrocytes and microglia in the spinal cord respond to harmful situations and release a plethora of signaling molecules, with protective and/or pathological functions (Milligan and Watkins, 2009). The role of glial cells is particularly important within sensory ganglia, where SGCs participate to both the generation of painful signals and the development of neuronal sensitization thanks to their close connections with sensory neurons with the generation of a vicious circle of hyperexcitability (Takeda et al., 2009). Therefore, it seems to be timely to move from "classical" antinociceptive approaches, mainly targeting neurons, to broader (and possibly more effective) strategies aimed at manipulating neuron-glia communication.
The purinergic system is one of the most intriguing, but yet not fully explored, signaling pathways involved in pain transmission. Adenine and uracil nucleotides are physiologically released as cotransmitters, and can be detected at high concentrations at injury sites as contributors to neuronal hypersensitivity (Burnstock, 2006). A clear pronociceptive role for the ionotropic ATPgated $\mathrm{P} 2 \mathrm{X}_{3}, \mathrm{P} 2 \mathrm{X}_{4}$ and $\mathrm{P} 2 \mathrm{X}_{7}$ receptor subtypes has been recognized (Kennedy, 2005). The $\mathrm{P}_{2} \mathrm{X}_{3}$ subtype is one of the most important pain transducing receptors expressed by neurons within sensory ganglia, as its activity is modulated by migraine mediators such as CGRP, NGF and BDNF (Fabbretti et al., 2006; D’Arco et al., 2007; Giniatullin et al., 2008; Simonetti et al., 2008). 


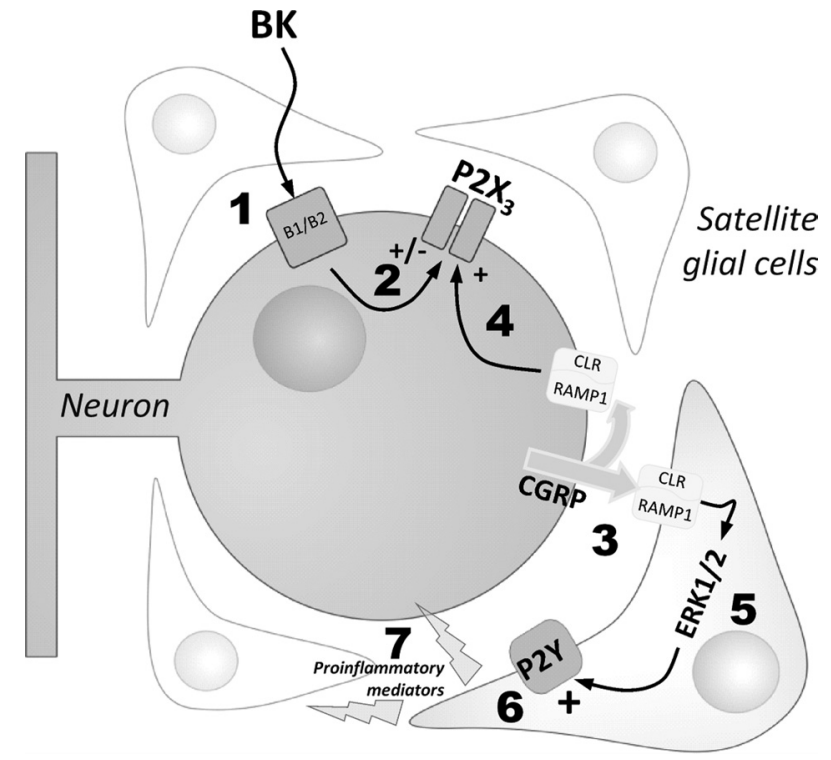

Figure 9. Schematic representation of BK-induced effects on purinergic transmission in trigeminal ganglia. By activating its specific neuronal receptors (1), BK modulates $P 2 X_{3}$ receptor function (2) (Ceruti et al., 2008), and induces the release of CGRP (3). CGRP can either act autocrinally on its neuronal receptors (4), leading to the upregulation of $\mathrm{P} 2 \mathrm{X}_{3}$ receptor function (Fabbretti et al., 2006), or paracrinally on the surrounding SGCs. Activation of the glial CGRP receptors in turn stimulates the ERK1/2 MAP kinase signaling pathway (5), and promotes P2Y receptor-mediated responses, as demonstrated by the potentiation of ADP- and UTP-induced increases in $\left[\mathrm{Ca}^{2+}\right]_{i}(6)$, which might be associated to the enhancement of purinergic sensitivity in SGCs. A significant release of pro/anti-inflammatory cytokines is also observed (7), which could further contribute to cell-to-cell communication within the ganglion. A significantly higher basal and stimulated GRP release, likely responsible for the upregulation of $P 2 X_{3}$ receptor signaling (Nair et al., 2010), together with an increased percentage of nucleotideresponding cells after exposure to BK were detected in trigeminal ganglia from Cav2.1 a1 R1920 mutant KI mice, which indicates the importance of generating and maintaining an enhanced proalgogenic tissue state in migraine (see Discussion for details).

Interestingly, neurons from $\mathrm{Ca}_{\mathrm{V}} 2.1 \alpha 1 \mathrm{R} 192 \mathrm{Q}$ mutant KI mice show $\mathrm{P} 2 \mathrm{X}_{3}$ receptor-mediated responses significantly larger than WT neurons (Nair et al., 2010), strengthening the link of this receptor channel with migraine pathophysiology.

Thus far, eight P2Y receptor subtypes are known (named $\mathrm{P} 2 \mathrm{Y}_{1,2,4,6,11,12,13,14}$ ), with both neuronal and glial localization in all the central and peripheral stations of pain transducing systems (Burnstock, 2009). Their role in nociception is still under debate with both potential analgesic and algogenic actions. For instance, although the activation of the uridine $\mathrm{P} 2 \mathrm{Y}_{2}$ receptor promotes CGRP release (Sanada et al., 2002), and facilitates capsaicininduced currents in rat dorsal root ganglia (DRG) (Gerevich and Illes, 2004), UTP and UDP were found to be analgesic when intrathecally injected to rats (Okada et al., 2002). Moreover, neuronal $\mathrm{P} 2 \mathrm{Y}_{1}$ receptors can downregulate $\mathrm{P} 2 \mathrm{X}_{3}$ receptor function in rat DRG (Gerevich et al., 2005), and its cognate ligand ADP can exert an antinociceptive role (Gerevich and Illes, 2004). Conversely, the selective inhibition of the ADP-sensitive $\mathrm{P}_{2} \mathrm{Y}_{12}$ receptor subtype in vivo significantly suppresses neuropathic pain following spinal nerve ligation (Tsuda et al., 2010).

The concept that $\mathrm{P} 2 \mathrm{Y}$ receptors may play a role in the pathogenesis of migraine pain is rather new. Their expression and function in the TG has been demonstrated earlier (Ruan and Burnstock, 2003; Weick et al., 2003), and our group has recently shown that a $24 \mathrm{~h}$ exposure to the proalgogenic agent BK potentiates P2Y receptors expressed by SGCs (Ceruti et al., 2008). Here we show that this effect seems to occur through CGRP release and
ERK1/2 activation, and that it is further amplified in cultures from $\mathrm{Ca}_{\mathrm{V}} 2.1 \alpha 1 \mathrm{R} 192 \mathrm{Q}$ mutant KI mice through the increased percentage of responding cells. It is worth mentioning that an acute exposure to BK does not exert any effect on glial P2Y receptors, while it enhances the amplitude of neuronal $\mathrm{P} 2 \mathrm{X}_{3}$-mediated responses (Ceruti et al., 2008). This suggests temporally distinct effects of $\mathrm{BK}$, with an immediate activation of $\mathrm{P} 2 \mathrm{X}$ receptors contributing to acute nociception, and a subsequent CGRPmediated upregulation of glial $\mathrm{P} 2 \mathrm{Y}$ receptors that may instead contribute to long-term maintenance of the TG proalgogenic state. Our results further suggest that the latter condition could rely on the release of various cytokines, chemokines, and growth factors, as was already demonstrated for $\mathrm{P}_{2} \mathrm{Y}_{2}$ receptor subtypes in astrocytes (Weisman et al., 2005). Nevertheless, at this stage, we cannot exclude that the observed plasticity of $\mathrm{P} 2 \mathrm{Y}$ receptors represents an attempt to counteract the pronociceptive effects of $\mathrm{BK}$ and CGRP, an issue that deserves further studies with selective block/silencing of these receptors in vivo or that different receptor subtypes (namely, the $\mathrm{P} 2 \mathrm{Y}_{1,12,13}$ and the $\mathrm{P} 2 \mathrm{Y}_{2,4}$ subtypes for ADP and UTP, respectively) might play opposite roles in the modulation of TG sensitivity.

$\mathrm{BK}$ has been demonstrated to activate sensory neurons (Calixto et al., 2000), increase the firing rate of second order neurons in the trigeminal nucleus caudalis (Ebersberger et al., 1997), and induce the release of proinflammatory molecules from TG neurons (Jenkins et al., 2003). Our observation that BK-induced effects on SGCs are mediated by the neuronal release of CGRP, and are completely abolished by the serotonin agonist sumatriptan, suggests that this whole molecular network could be involved in migraine pathophysiology. In fact, during migraine attacks, CGRP is released by TG afferents at the meninges, where they may contribute to neurogenic inflammation and induce painassociated vasodilatation (Messlinger et al., 1995; Tepper and Stillman, 2008). The increased CGRP plasma levels in migraineurs (Goadsby et al., 1990), which return to baseline after administration of migraine abortive drugs (such as sumatriptan; Durham and Russo, 2002), the fact that injection of CGRP triggers migraine pain in sensitive subjects (Lassen et al., 2002), as well as the efficacy of CGRP antagonists in treating migraine patients (Olesen et al., 2004), demonstrate the important role of CGRP in migraine pathophysiology. More recently, an additional peripheral role for CGRP in sensitizing TG neurons and modulating crosstalk with SGCs has emerged: CGRP releases BDNF from TG neurons (Buldyrev et al., 2006; Simonetti et al., 2008), and stimulates NO and cytokine release form SGCs (Durham, 2008). It is worth mentioning that CGRP acting on TG neurons promotes its own synthesis and release through MAP kinase activation, so that selective MAP kinase inhibitors have been proposed as novel approaches for dampening CGRP levels in migraine (Durham and Russo, 2002; Tajti et al., 2011). Our results provide support for this hypothesis, by demonstrating that ERK1/2 MAP kinase inhibition also blocks the downstream effects of CGRP on SCGs, with a possible additive analgesic effect. This has already been demonstrated for CGRP-mediated induction of iNOS and production of NO in SGCs, which are also dependent on MAP kinase activation (Vause and Durham, 2009).

Our data show, for the first time, an increased basal and stimulated CGRP release from TG cultures from $\mathrm{Ca}_{\mathrm{V}} 2.1 \alpha 1 \mathrm{R} 192 \mathrm{Q}$ mutant KI mice that express a mutation typical of FHM1 (Ophoff et al., 1996; van den Maagdenberg et al., 2004, 2007). These FHM1 transgenic mice were previously shown to exhibit an enhanced neuronal calcium influx and glutamate release from 
cortical neurons, which seemed to explain their increased susceptibility to CSD (van den Maagdenberg et al., 2004, 2010; Tottene et al., 2009), the electrophysiological correlate of migraine aura (Lauritzen, 1994). Although a role for CSD in generating migraine headaches is still debated, its induction in experimental animals activates brain centers involved in generating headaches (Bolay et al., 2002). Our results suggest that, in trigeminal cultures from such KI mice, the detected increase in basal CGRP release was due to overactive $\mathrm{Ca}_{\mathrm{V}} 2.1$ calcium channels. We also hypothesize that the presence of a basal proinflammatory milieu within the KI TGs might lower the threshold for neuronal firing. The fact that the already elevated TG CGRP levels release can be further enhanced by neuronal stimulation with $\mathrm{BK}$ or $\mathrm{KCl}$ suggests that this pathway might contribute to amplification of the basal proinflammatory state and facilitate a migraine attack. This hypothesis is supported by the observed increased percentage of nucleotideresponding glial cells upon BK exposure.

The importance of the CGRP pathway in FHM1 patients has been questioned since, in a pilot study, these patients showed sensitivity to CGRP infusion similar to control subjects (Hansen et al., 2008). On the basis of our data on the delayed and indirect effects of CGRP, we would argue that the role of CGRP in peripheral neurogenic inflammation within TGs should be investigated with suitable protocols that take into account the complex time dependence of the responses. In fact, in the presence of high levels of CGRP, neuronal $\mathrm{P} 2 \mathrm{X}_{3}$ receptors show late functional potentiation (Fabbretti et al., 2006; Simonetti et al., 2008), and activation of $\mathrm{P} 2 \mathrm{X}_{3}$ receptors on $\mathrm{KI}$ neurons evokes a much larger calcium influx (Nair et al., 2010). The present data suggest that overactive glial P2Y receptors may significantly contribute to pain transduction and that they represent a novel target for pharmacological modulation of migraine pain.

\section{References}

Bianco F, Fumagalli M, Pravettoni E, D’Ambrosi N, Volonte C, Matteoli M, Abbracchio MP, Verderio C (2005) Pathophysiological roles of extracellular nucleotides in glial cells: differential expression of purinergic receptors in resting and activated microglia. Brain Res Brain Res Rev 48:144-156.

Bolay H, Reuter U, Dunn AK, Huang Z, Boas DA, Moskowitz MA (2002) Intrinsic brain activity triggers trigeminal meningeal afferents in a migraine model. Nat Med 8:136-142.

Buldyrev I, Tanner NM, Hsieh HY, Dodd EG, Nguyen LT, Balkowiec A (2006) Calcitonin gene-related peptide enhances release of native brainderived neurotrophic factor from trigeminal ganglion neurons. J Neurochem 99:1338-1350.

Burnstock G (2006) Purinergic P2 receptors as targets for novel analgesics. Pharmacol Ther 110:433-454.

Burnstock G (2009) Purinergic receptors and pain. Curr Pharm Des 15:1717-1735.

Calixto JB, Cabrini DA, Ferreira J, Campos MM (2000) Kinins in pain and inflammation. Pain 87:1-5.

Capuano A, De Corato A, Lisi L, Tringali G, Navarra P, Dello Russo C (2009) Proinflammatory-activated trigeminal satellite cells promote neuronal sensitization: relevance for migraine pathology. Mol Pain 5:43.

Ceruti S, Fumagalli M, Villa G, Verderio C, Abbracchio MP (2008) Purinoceptor-mediated calcium signaling in primary neuron-glia trigeminal cultures. Cell Calcium 43:576-590.

D’Arco M, Giniatullin R, Simonetti M, Fabbro A, Nair A, Nistri A, Fabbretti E (2007) Neutralization of nerve growth factor induces plasticity of ATP-sensitive P2X3 receptors of nociceptive trigeminal ganglion neurons. J Neurosci 27:8190-8201.

Durham PL (2008) Inhibition of calcitonin gene-related peptide function: a promising strategy for treating migraine. Headache 48:1269-1275.

Durham PL, Russo AF (2002) New insights into the molecular actions of serotonergic antimigraine drugs. Pharmacol Ther 94:77-92.

Ebersberger A, Ringkamp M, Reeh PW, Handwerker HO (1997) Record- ings from brain stem neurons responding to chemical stimulation of the subarachnoid space. J Neurophysiol 77:3122-3133.

Ebersberger A, Averbeck B, Messlinger K, Reeh PW (1999) Release of substance $\mathrm{P}$, calcitonin gene-related peptide and prostaglandin $\mathrm{E} 2$ from rat dura mater encephali following electrical and chemical stimulation in vitro. Neuroscience 89:901-907.

England S, Heblich F, James IF, Robbins J, Docherty RJ (2001) Bradykinin evokes a $\mathrm{Ca}^{2+}$-activated chloride current in non-neuronal cells isolated from neonatal rat dorsal root ganglia. J Physiol 530:395-403.

Fabbretti E, D’Arco M, Fabbro A, Simonetti M, Nistri A, Giniatullin R (2006) Delayed upregulation of ATP P2X3 receptors of trigeminal sensory neurons by calcitonin gene-related peptide. J Neurosci 26:6163-6171.

Gerevich Z, Illes P (2004) P2Y receptors and pain transmission. Purinergic Signal 1:3-10.

Gerevich Z, Müller C, Illes P (2005) Metabotropic P2Y1 receptors inhibit $\mathrm{P} 2 \mathrm{X} 3$ receptor-channels in rat dorsal root ganglion neurons. Eur J Pharmacol 521:34-38.

Giniatullin R, Nistri A, Fabbretti E (2008) Molecular mechanisms of sensitization of pain-transducing $\mathrm{P} 2 \mathrm{X} 3$ receptors by the migraine mediators CGRP and NGF. Mol Neurobiol 37:83-90.

Goadsby PJ, Edvinsson L, Ekman R (1990) Vasoactive peptide release in the extracerebral circulation of humans during migraine headache. Ann Neurol 28:183-187.

Goadsby PJ, Lipton RB, Ferrari MD (2002) Migraine-current understanding and treatment. N Engl J Med 346:257-270.

Hanani M (2005) Satellite glial cells in sensory ganglia: from form to function. Brain Res Brain Res Rev 48:457-476.

Hansen JM, Thomsen LL, Olesen J, Ashina M (2008) Calcitonin generelated peptide does not cause the familial hemiplegic migraine phenotype. Neurology 71:841-847.

Headache Classification Subcommittee of the International Headache Society (2004) The international classification of headache disorders: second edition. Cephalalgia 24 [Suppl 1]:9-160.

Jarvis MF (2010) The neural-glial purinergic receptor ensemble in chronic pain states. Trends Neurosci 33:48-57.

Jenkins DW, Sellers LA, Feniuk W, Humphrey PP (2003) Characterization of bradykinin-induced prostaglandin E2 release from cultured rat trigeminal ganglion neurones. Eur J Pharmacol 469:29-36.

Kennedy C (2005) P2X receptors: targets for novel analgesics? Neuroscientist 11:345-356.

Lassen LH, Haderslev PA, Jacobsen VB, Iversen HK, Sperling B, Olesen J (2002) CGRP may play a causative role in migraine. Cephalalgia 22:54-61.

Lauritzen M (1994) Pathophysiology of the migraine aura. The spreading depression theory. Brain 117:199-210.

Leeb-Lundberg LM, Marceau F, Müller-Esterl W, Pettibone DJ, Zuraw BL (2005) International union of pharmacology. XLV. Classification of the kinin receptor family: from molecular mechanisms to pathophysiological consequences. Pharmacol Rev 57:27-77.

Lennerz JK, Rühle V, Ceppa EP, Neuhuber WL, Bunnett NW, Grady EF, Messlinger K (2008) Calcitonin receptor-like receptor (CLR), receptor activity-modifying protein 1 (RAMP1), and calcitonin gene-related peptide (CGRP) immunoreactivity in the rat trigeminovascular system: differences between peripheral and central CGRP receptor distribution. J Comp Neurol 507:1277-1299.

Li J, Vause CV, Durham PL (2008) Calcitonin gene-related peptide stimulation of nitric oxide synthesis and release from trigeminal ganglion glial cells. Brain Res 1196:22-32.

Meng J, Wang J, Lawrence G, Dolly JO (2007) Synaptobrevin I mediates exocytosis of CGRP from sensory neurons and inhibition by botulinum toxins reflects their anti-nociceptive potential. J Cell Sci 120:2864-2874.

Messlinger K (2009) Migraine: where and how does the pain originate? Exp Brain Res 196:179-193.

Messlinger K, Hanesch U, Kurosawa M, Pawlak M, Schmidt RF (1995) Calcitonin gene related peptide released from dural nerve fibers mediates increase of meningeal blood flow in the rat. Can J Physiol Pharmacol 73:1020-1024.

Milligan ED, Watkins LR (2009) Pathological and protective roles of glia in chronic pain. Nat Rev Neurosci 10:23-36.

Nair A, Simonetti M, Birsa N, Ferrari MD, van den Maagdenberg AM, Giniatullin R, Nistri A, Fabbretti E (2010) Familial hemiplegic migraine $\mathrm{Ca}_{\mathrm{v}} 2.1$ channel mutation R192Q enhances ATP-gated P2X 3 receptor ac- 
tivity of mouse sensory ganglion neurons mediating trigeminal pain. Mol Pain 6:48.

Okada M, Nakagawa T, Minami M, Satoh M (2002) Analgesic effects of intrathecal administration of P2Y nucleotide receptor agonists UTP and UDP in normal and neuropathic pain model rats. J Pharmacol Exp Ther 303:66-73.

Olesen J, Diener HC, Husstedt IW, Goadsby PJ, Hall D, Meier U, Pollentier S, Lesko LM (2004) Calcitonin gene-related peptide receptor antagonist BIBN 4096 BS for the acute treatment of migraine. N Engl J Med 350:1104-1110.

Ophoff RA, Terwindt GM, Vergouwe MN, van Eijk R, Oefner PJ, Hoffman SM, Lamerdin JE, Mohrenweiser HW, Bulman DE, Ferrari M, Haan J, Lindhout D, van Ommen GJ, Hofker MH, Ferrari MD, Frants RR (1996) Familial hemiplegic migraine and episodic ataxia type- 2 are caused by mutations in the $\mathrm{Ca}^{2+}$ channel gene CACNL1A4. Cell 87:543-552.

Ruan HZ, Burnstock G (2003) Localisation of P2Y1 and P2Y4 receptors in dorsal root, nodose and trigeminal ganglia of the rat. Histochem Cell Biol 120:415-426.

Sanada M, Yasuda H, Omatsu-Kanbe M, Sango K, Isono T, Matsuura H, Kikkawa $\mathrm{R}$ (2002) Increase in intracellular $\mathrm{Ca}^{2+}$ and calcitonin generelated peptide release through metabotropic $\mathrm{P} 2 \mathrm{Y}$ receptors in rat dorsal root ganglion neurons. Neuroscience 111:413-422.

Simonetti M, Fabbro A, D'Arco M, Zweyer M, Nistri A, Giniatullin R, Fabbretti E (2006) Comparison of P2X and TRPV1 receptors in ganglia or primary culture of trigeminal neurons and their modulation by NGF or serotonin. Mol Pain 2:11.

Simonetti M, Giniatullin R, Fabbretti E (2008) Mechanisms mediating the enhanced gene transcription of $\mathrm{P} 2 \mathrm{X} 3$ receptor by calcitonin gene-related peptide in trigeminal sensory neurons. J Biol Chem 283:18743-18752.

Tajti J, Kuris A, Vécsei L, Xu CB, Edvinsson L (2011) Organ culture of the trigeminal ganglion induces enhanced expression of calcitonin generelated peptide via activation of extracellular signal-regulated protein kinase 1/2. Cephalalgia 31:95-105.

Takeda M, Takahashi M, Matsumoto S (2009) Contribution of the activation of satellite glia in sensory ganglia to pathological pain. Neurosci Biobehav Rev 33:784-792.

Tepper SJ, Stillman MJ (2008) Clinical and preclinical rationale for CGRPreceptor antagonists in the treatment of migraine. Headache 48:1259-1268.

Thalakoti S, Patil VV, Damodaram S, Vause CV, Langford LE, Freeman SE, Durham PL (2007) Neuron-glia signaling in trigeminal ganglion: implications for migraine pathology. Headache 47:1008-1023.
Tottene A, Conti R, Fabbro A, Vecchia D, Shapovalova M, Santello M, van den Maagdenberg AM, Ferrari MD, Pietrobon D (2009) Enhanced excitatory transmission at cortical synapses as the basis for facilitated spreading depression in $\mathrm{Ca}(\mathrm{v}) 2.1$ knockin migraine mice. Neuron 61:762-773.

Tsuda M, Tozaki-Saitoh H, Inoue K (2010) Pain and purinergic signaling. Brain Res Rev 63:222-232.

van den Maagdenberg AM, Pietrobon D, Pizzorusso T, Kaja S, Broos LA, Cesetti T, van de Ven RC, Tottene A, van der Kaa J, Plomp JJ, Frants RR, Ferrari MD (2004) A Cacnala knockin migraine mouse model with increased susceptibility to cortical spreading depression. Neuron 41:701-710

van den Maagdenberg AM, Haan J, Terwindt GM, Ferrari MD (2007) Migraine: gene mutations and functional consequences. Curr Opin Neurol 20:299-305.

van den Maagdenberg AM, Pizzorusso T, Kaja S, Terpolilli N, Shapovalova M, Hoebeek FE, Barrett CF, Gherardini L, van de Ven RC, Todorov B, Broos LA, Tottene A, Gao Z, Fodor M, De Zeeuw CI, Frants RR, Plesnila N, Plomp JJ, Pietrobon D, Ferrari MD (2010) High cortical spreading depression susceptibility and migraine-associated symptoms in $\mathrm{Ca}(\mathrm{v}) 2.1$ S218L mice. Ann Neurol 67:85-98.

Vause CV, Durham PL (2009) CGRP stimulation of iNOS and NO release from trigeminal ganglion glial cells involves mitogen-activated protein kinase pathways. J Neurochem 110:811-821.

Vause CV, Durham PL (2010) Calcitonin gene-related peptide differentially regulates gene and protein expression in trigeminal glia cells: Findings from array analysis. Neurosci Lett 473:163-167.

Villa G, Fumagalli M, Verderio C, Abbracchio MP, Ceruti S (2010) Expression and contribution of satellite glial cells purinoceptors to pain transmission in sensory ganglia: an update. Neuron Glia Biol 6:31-42.

Watkins LR, Maier SF (2003) GLIA: A novel drug discovery target for clinical pain. Nat Rev Drug Discov 2:973-985.

Weick M, Cherkas PS, Härtig W, Pannicke T, Uckermann O, Bringmann A, Tal M, Reichenbach A, Hanani M (2003) P2 receptors in satellite glial cells in trigeminal ganglia of mice. Neuroscience 120:969-977.

Weisman GA, Wang M, Kong Q, Chorna NE, Neary JT, Sun GY, González FA, Seye CI, Erb L (2005) Molecular determinants of P2Y2 nucleotide receptor function: implications for proliferative and inflammatory pathways in astrocytes. Mol Neurobiol 31:169-183.

Xiao Y, Richter JA, Hurley JH (2008) Release of glutamate and CGRP from trigeminal ganglion neurons: role of calcium channels and 5-HT1 receptor signaling. Mol Pain 4:12. 